\title{
EMERGING TRENDS IN GREENHOUSE GAS THRESHOLDS OF SIGNIFICANCE FOR USE UNDER THE CALIFORNIA ENVIRONMENTAL QUALITY ACT
}

\author{
A Thesis \\ presented to \\ the Faculty of California Polytechnic State University, \\ San Luis Obispo
}

In Partial Fulfillment

of the Requirements for the Degree

Master of City and Regional Planning/Master of Science in Engineering (Transportation Planning Specialization) in the College of Architecture

by

Nancy Mathison

December 2010 
(c) 2010

Nancy Mathison

ALL RIGHTS RESERVED 


\section{COMMITTEE MEMBERSHIP}

TITLE:

AUTHOR:

DATE SUBMITTED:

COMMITTEE CHAIR:

COMMITTEE MEMBER:

COMMITTEE MEMBER:
Emerging Trends in Greenhouse Gas Thresholds of Significance for Use Under The California Environmental Quality Act

Nancy Mathison

December 2010

Adrienne Greve, Assistant Professor

Michael Boswell, Associate Professor

Aeron Arlin Genet, Manager of Planning \& Outreach Division, San Luis Obispo County Air Pollution Control District 


\begin{abstract}
Emerging Trends in Greenhouse Gas Thresholds of Significance for Use Under The California

Environmental Quality Act

Nancy Mathison
\end{abstract}

This study determined the state of the practice and emerging trends in developing greenhouse gas (GHG) thresholds of significance for use under the California Environmental Policy Act (CEQA). To describe the adopted, proposed or considered approaches for developing thresholds of significance by air districts and the thought processes behind these decisions, information was obtained through surveys and phone interviews from twelve employees of air districts in California, State agencies, and consultants that are considered experts on this issue. The results of this study include a comparison matrix of the approaches of the three air districts that have adopted or proposed GHG thresholds of significance, and identification of the common themes from air districts' responses that do not have adopted or proposed thresholds. While the development of GHG thresholds of significance is an evolving practice, emerging trends in this practice were identified. These trends include providing flexibility in options, an emphasis on programmatic approaches and a preference of including bright-line thresholds and efficiency thresholds. Furthermore, this paper concludes that while the three air districts that have proposed or adopted thresholds have laid the groundwork for other districts, some of the approaches or the thresholds themselves may not be easily transferable to other districts based on regional differences. This research provides insight into how GHG emissions might be addressed in CEQA documents throughout the State.

Keywords: Greenhouse gas (GHG) Thresholds of Significance, California Climate Change, California Environmental Quality Act (CEQA) Guidelines, Air Pollution Control District (APCD), Air Quality Management District (AQMD), AB 32, SB 97. 


\section{ACKNOWLEDGMENTS}

This research effort has been an enriching experience that would not have been possible without the educational and professional environment fostered by the City and Regional Planning Department at California Polytechnic State University, San Luis Obispo and the San Luis Obispo County Air Pollution Control District (SLOAPCD). First and foremost, I would like to express my gratitude to Assistant Professor Adrienne Greve for her patience, motivation and unwavering support over the past year. I am also thankful to SLOAPCD Planning and Outreach Division Manager Aeron Arlin Genet for her time, encouragement and expert guidance on air quality topics. A special thanks is also due to Associate Professor Michael Boswell for his assistance and knowledge related to public policy research. I would also like to thank Curtis Alling, AICP, Principal of Ascent Environmental, Inc. and Jeane Berry, Air Quality Planner/Analyst at the Sacramento Metropolitan Air Quality Management District (SMAQMD) for providing specialized opinions and information contributing to the results of this study. Thank you particularly to all the individuals in California that have anonymously participated in this study. It has been

a pleasure to interact with so many of the individuals throughout the state that are dedicated to improving the air quality, environment and future for all Californians. 


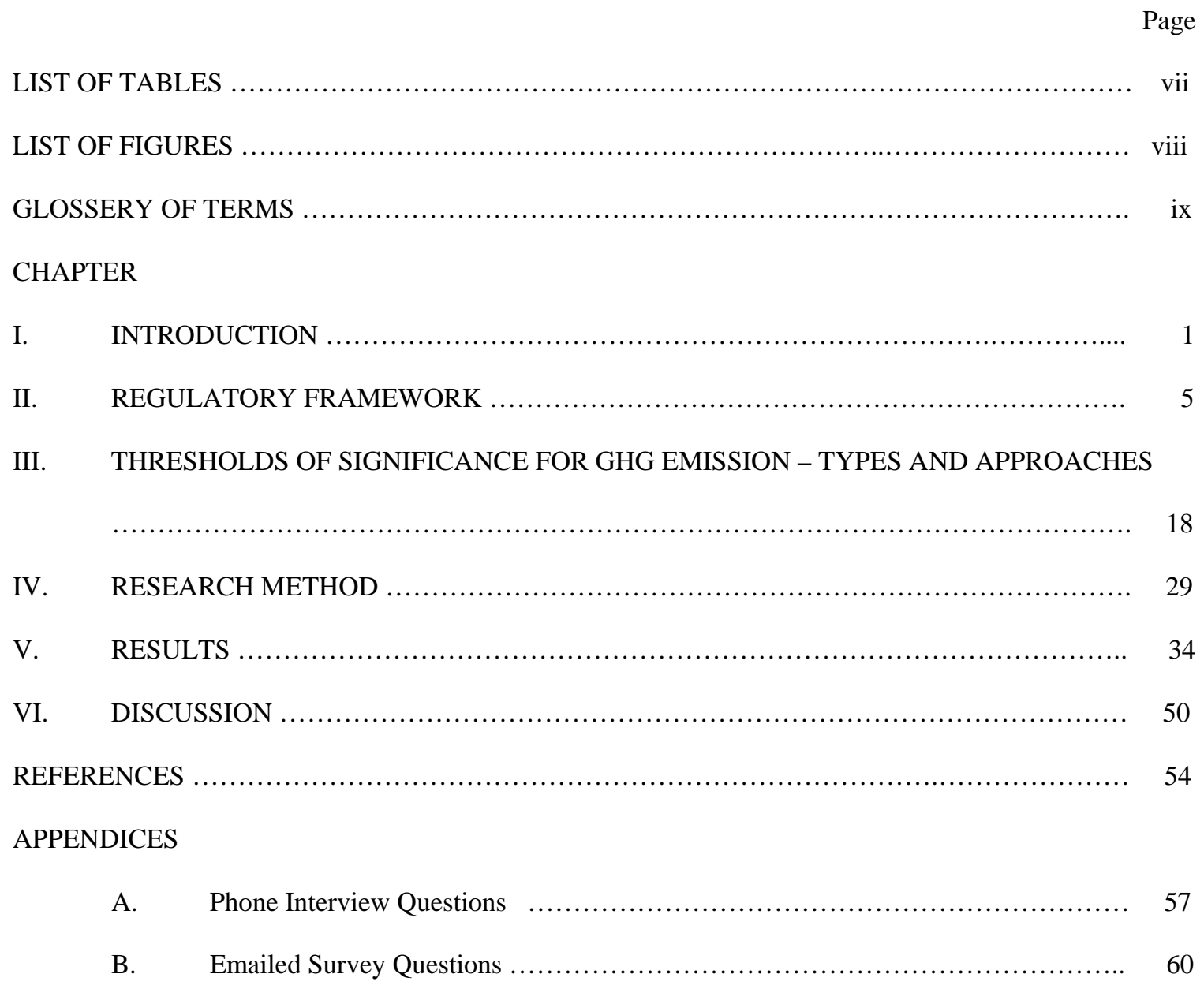




\section{LIST OF TABLES}

Table

Page

1. Counties, Area and Population Characteristics of the Bay Area, South Coast and San Joaquin

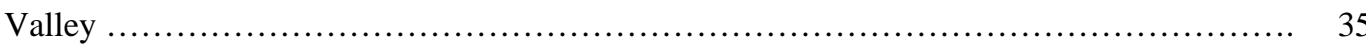

2. Adopted or Proposed GHG Thresholds of Significance by California Air Districts ........... 36 


\section{LIST OF FIGURES}

Figure Page

1. Navigating BAAQMD’s Threshold of Significance for GHG Emissions ................... 40

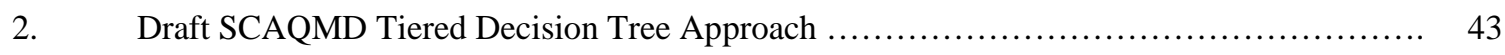




\section{GLOSSERY OF TERMS}

Business As Usual (BAU) projected emissions - emissions that would have occurred in the absence of the mandated reductions

Best Performance Standards (BPS) - the most effective, achievable in practice standards those are economically feasible

Bright-line threshold - a numerical level under which a project's emissions will typically be considered less than significant

Carbon Dioxide equivalent (CO2e) - greenhouse gases expressed in terms of their equivalence to $\mathrm{CO} 2$, based on their global warming potential

Climate Action Plan (CAP) - a plan for reducing a community’s GHG emissions that may include a GHG inventory, a GHG emissions reduction target, a set of GHG reduction strategies or measures and procedures for monitoring progress towards the stated goals

Greenhouse Gas Reduction Strategy - the collective set of climate action policies, ordinances and other programs that reduce a community’s GHG emissions; to qualify as a strategy that provides streamlining under CEQA, these plans, policies and programs generally must be consistent with State CEQA Guidelines § 15183.5 (b)

Service Population (SP) - the sum of the residential population and the number of jobs directly supported by the project or plan 


\section{INTRODUCTION}

"We simply must do everything we can in our power to slow down global warming before it is too late. The science is clear. The global warming debate is over.” - Governor Arnold Schwarzenegger during his signing of The California Global Warming Solutions Act, Assembly Bill (AB) 32. (MSNBC, 2006, para. 3).

The adoption of what is now widely known as California's landmark climate law ushered in “a bold new era of environmental protection” as foreseen by Governor Arnold Schwarzenegger in 2006 (MSNBC, 2006, para. 1). The California Global Warming Solutions Act, Assembly Bill (AB) 32, which established a process for California to reduce its statewide greenhouse gas (GHG) emissions to 1990 levels by 2020, set into motion a series of plans, programs, standards and other legislation that address climate change in the State. As the $15^{\text {th }}$ largest emitter of GHG emissions globally, California represents $2 \%$ of worldwide emissions (CARB, 2008). While climate change is a global problem, California is taking steps at every level of government to address its contribution of GHG emissions.

As part of this effort to reduce GHG emissions, local governments began to focus attention on GHG emissions attributed to land use decisions. Emissions from this sector represent a significant amount of the total GHG emissions in the State. Based on the projected growth of statewide GHG emissions between 1990 and 2020 and accounting for planned implementation of statewide GHG reduction programs, a 2.8 percent reduction of GHG emissions is required from land use-driven sectors to meet the goal of AB 32 (BAAQMD, 2009). The land use-driven sectors represent the sectors that are influenced by future local land use decisions. While this percentage may seem small, it represents the portion of GHG emissions that can only be reduced through local efforts. Since local governments have authority over land use decisions, they play a crucial role in reducing GHG emissions from land use related sources. Local governments have numerous tools for implementing GHG reduction measures and adaptation strategies respond to the threat of climate change.

The California Environmental Quality Act (CEQA) requires public agencies to analyze the potential environmental impacts of future discretionary actions, plans or projects and to mitigate those impacts to the 
extent feasible if they are determined to be significant. Land use designations are included in those that require scrutiny under CEQA. The US EPA's endangerment finding, AB 32 and SB 97 legislation and 2010 CEQA Guidelines Update affirm that "climate change is an environmental impact within the scope of CEQA” (AG, 2010, para. 2). However, lead agencies continue to be uncertain about how to address climate change in CEQA documents, and in particular, how to determine what level of GHG emissions constitutes a significant impact under CEQA. For guidance on this topic, many lead agencies have turned to local air districts for assistance.

Climate change refers to the lasting significant changes in temperature, precipitation or wind (EPA, 2010). Unequivocal evidence of climate change includes global increases in air and ocean temperatures, sea level rise and decreases in snowpack (IPCC, 2007). These changes pose an endangerment to the public health and welfare (US EPA, 2009). As acknowledged by the California Health and Safety Code, climate change "poses a serious threat to the economic well-being, public health, natural resources and the environment in California” (California Health and Safety Code § 38501, subdivision (a)). In particular, California faces disproportionate impacts resulting from climate change such as a greater intensity of wildfires, increased flood risks, decreases in water supply, coastline erosion and higher concentrations of harmful pollutants (CARB, 2008).

Climate change is the result of substantial increases in GHG emissions from natural factors, processes and anthropogenic sources (EPA, 2010, para. 3). As defined by the US EPA and AB 32, GHG emissions include carbon dioxide (CO2), methane (CH4), nitrous oxide (N2O), hydrofluorocarbons (HFCs), perfluorocarbons (PFCs), and sulfur hexafluoride (SF6) ((Health \& Safety Code, § 38500; EPA, Endangerment Finding, 74 Fed. Reg. 66496, 66517). These GHG emissions are commonly referred to by their global warming potential (GWP), expressed in terms of their equivalence to $\mathrm{CO} 2$ (CO2e).

As the entity charged with implementing State air quality regulations, air districts typically provide guidance to lead agencies on the level of emissions for a particular pollutant that typically constitutes a significant impact under CEQA. Air districts have experience with setting thresholds for pollutants that 
both directly impact public health and the environment and for pollutants that cumulatively contribute to adverse impacts. Climate change is the result of the cumulative emissions from numerous past, current and future sources, which are not large enough to cause an environmental impact on their own (CAPCOA, 2008). Three out of thirty-five air districts in the State have adopted or have proposed GHG emission thresholds for use in the cumulative analysis of GHG emissions. Lead agencies within these air basins where air districts have developed and adopted thresholds are encouraged to adopt and use these thresholds as guidance in determining the significance of projects’ GHG emissions (CNRA, 2009).

While three air districts have adopted guidance, most are in the midst of deciding how to proceed. To better understand what guidance is available to lead agencies, this research provides an overview of the guidance on GHG thresholds of significance from State agencies and legal and air quality experts in the field. It also describes the state of the practice for developing GHG thresholds by comparing the thresholds, approaches, and implementation and development processes used by the three air districts that have adopted or proposed GHG thresholds of significance. Finally, a comparison of survey responses from air districts that have not yet adopted threshold provides insight into what approaches they might take in the near future. Analyzing what GHG thresholds that regional air districts have adopted, proposed or are considering provides a more comprehensive picture of how GHG emissions will be addressed in CEQA documents statewide. Through the following sections, this paper provides a snapshot in time of the thought process behind what GHG thresholds of significance air districts have adopted or are considering and identifies the predominate emerging trends.

II. REGULATORY FRAMEWORK - Summarizes key legislation, guidance documents available on GHG thresholds and the main players involved in this discussion at all levels of government

III. THRESHOLD TYPES AND APPROACHES - Summarizes the various threshold types and approaches described in guidance documents

IV. METHODOLOGY - Describes the methodology used to conduct the research for this study 
V. RESULTS - Describes the state of the practice for developing GHG thresholds of significance through a comparison of adopted or proposed approaches and perspectives

VI. DISCUSSION - Identifies commonalities and trends; addresses the need for more assistance to air districts and future research 


\section{REGULATORY FRAMEWORK}

The following regulatory framework provides the political context for how GHG emissions are being addressed at all levels of government and how GHG thresholds of significance for use in CEQA analysis fit into this structure. In doing so, this section covers the key legislation and guidance documents available on GHG thresholds and the main players involved in climate change discussions at various levels of government. Climate change is being addressed from international coordination to individual cities at levels in between. As such, climate policy, planning and actions are occurring concurrently through top-down and bottom-up strategies with varying levels of success. While this paper focuses on what actions air districts are taking at the regional level, it is important to understand the context surrounding the decisions that are being made. The following regulatory framework is organized in a top-down format, starting at the international level and culminating at the State and local level.

\section{International}

Countries across the globe have been negotiating internationally to develop GHG emission targets since the 1990’s. Given the global nature of climate change, cooperation among industrialized and developing nations is seen as key to make progress towards stabilizing climate change. While an international agreement to reduce GHG emissions between the US and other top GHG emitting nations has not been successful, the proposed target reductions developed at the international level have been adopted in the United States at the local, regional and state levels.

United Nations Framework Convention on Climate Change. The United Nations Framework Convention on Climate Change (UNFCCC) is an international treaty aimed at reducing global greenhouse gas emissions to a non-dangerous level. The UNFCCC was established in 1994 and has 192 participating 
countries, including the United States. The treaty calls for establishing protocols to set mandatory limits on greenhouse gas emissions. The Kyoto Protocol is one such agreement established by the UNFCCC.

Kyoto Protocol. The Kyoto Protocol is an international agreement of the UNFCC that commits 37 participating countries to binding targets to reduce greenhouse gas emissions. The reductions from these countries correspond to "an average of five percent against 1990 levels over the five-year period 20082012” (UNFCCC, 2010, p.1). Although the United States signed the Kyoto Protocol on December 11, 1998, it remains unenforceable since the treaty has not been ratified by Congress. While the US does not have legally binding standards for GHG emissions, many cities, counties, regional governments and states in the US have adopted the Kyoto Protocol targets or rely on its scientific backing to justify climate-related regulations or plans.

COP15 Accords. The Conferences of the Parties (COP) has been convening annually since the UNFCCC was established to review and access the progress of participating countries to meet emission reduction targets and to negotiate the guiding protocols. The fifteenth session of the COP took place in Copenhagen, Denmark, in 2009. The main goal for the COP 15 was to establish a global climate change agreement to supersede the Kyoto Protocol that expires in 2012. The negotiations failed to produce legally binding targets for reducing greenhouse gas emissions beyond 2012. On the last day of negotiations, the delegates approved a motion to "take note of" the Copenhagen Accord, a document drafted by the US, China, India, South Africa, and Brazil that outlines non-binding GHG emission reduction targets and commitments. While the United States has submitted reduction targets of 17 percent by 2020 to the UNFCCC, the US Senate failed in 2010 to pass through the Senate a comprehensive climate change plan on how to reach these targets.

\section{Federal}

While the United States has been unsuccessful in adopting comprehensive climate legislation, it has adopted numerous other regulations and allocated funding to help curb climate change. In addition, federal 
court rulings have compelled federal agencies to regulate GHG emissions. Much of what has occurred at the national level has allowed California to continue to implement its climate change measures.

Massachusetts v. EPA: On April 2, 2007, the U.S. Supreme Court found that GHGs are air pollutants as defined by the Clean Air Act. The Supreme Court held that the US EPA Administrator must revisit their decision not to regulation GHG emissions. Specifically, the court required the US EPA Administrator to determine whether or not emissions of greenhouse gases from motor vehicles cause or contribute to air pollution and to determine if GHG emissions might reasonably be anticipated to endanger public health or welfare (Massachusetts v. EPA, 2007).

Executive Order 13432. As a result of the Massachusetts v. EPA decision, President Bush issued an executive order on May 16, 2007 to "ensure the coordinated and effective exercise of the authorities of the President and the heads of the Department of Transportation, the Department of Energy, and the Environmental Protection Agency to protect the environment with respect to greenhouse gas emissions from motor vehicles, non-road vehicles, and non-road engines, in a manner consistent with sound science, analysis of benefits and costs, public safety, and economic growth” (Exec. Order No. 13432, 2007, p. 27717). This executive order gave further support for the U.S. EPA to conclude that GHG emissions endanger public health and welfare and that these emissions from vehicles contribute to climate change.

\section{USEPA Endangerment and Cause or Contribute Findings for Greenhouse Gases under the Clean Air}

Act. Following the Massachusetts v. EPA decision and E.O. 13432, the EPA Administrator was compelled to review the position to not regulate GHG emissions under the Clean Air Act (CAA). Pursuant to section 202(a) of the CAA, the US EPA Administrator found that GHG emissions endanger the public health and welfare (US EPA, 2009). These “air pollutants” include carbon dioxide (CO2), methane (CH4), nitrous oxide (N2O), hydrofluorocarbons (HFCs), perfluorocarbons (PFCs), and sulfur hexafluoride (SF6). As the contribute finding, the Administrator found that GHG emissions from vehicle tailpipes contribute to climate change (US EPA, 2009). These findings were made effective on January 14, 2010. 
These findings have laid the groundwork for the EPA and other governmental bodies to impose regulations on sources of greenhouse gas emissions. For example, following this finding, the EPA and National Highway Traffic Safety Administration (NHTSA) set standards requiring passenger cars, light-duty trucks, and medium-duty passenger vehicles with model years from 2012-2016 to meet a feet-wide average of 250 grams of carbon dioxide emissions per mile, which is approximately $35.5 \mathrm{mpg}$. It is estimated that greenhouse gas emissions will be reduced by 960 million metric tons over the lifetime of the vehicles sold under this regulation (US EPA, 2010).

Although California already recognizes that GHG emissions endangered public health and welfare, the US EPA's affirmation of this finding reinforces the evidence supporting California goals to reduce GHG emissions. In addition, the contribute finding provided further evidence to grant California a waiver to regulated GHG emissions from vehicles as part of its AB 32 Scoping Plan measures.

USEPA Final Mandatory Reporting of Greenhouse Gases Rule. The USEPA Final Mandatory Reporting of Greenhouse Gases Rule took effect on December 29, 2009. The rule requires large sources and suppliers that emit 25,000 MT of CO2E per year in the United States to report their greenhouse gas emissions annually. This represents about 85 percent of all domestically emitted GHGs and approximately 10,000 facilities. The purpose of the rule is "to collect accurate and timely emissions data to guide future policy decisions on climate change” (US EPA, 2010b, para. 7). The 25,000 MT level correlates with the Mandatory Reporting Rule set by the California Air Resources Board (ARB). Additionally, this number was initially proposed (though not adopted) by both the Bay Area Air Quality Management District (Bay Area) and the South Coast Air Quality Management District (South Coast) as a maximum GHG emissions limit for projects to act as a backstop when using efficiency-based or other types of thresholds.

\section{State and Local}

California is widely recognized nationally as a leader on climate change policy and planning (Climate Action Reserve, 2010). California has passed numerous laws, plans and programs at all levels of government to reduce GHG emissions. Many of these laws or practices have been adopted by other states 
that are following California's lead. In California, the courts have also played an integral role in this process by defining how climate change laws are to be interpreted and implemented.

Executive Order S-3-05. Governor Arnold Schwarzenegger signed an executive order in 2005 to establish targets to reduce greenhouse gases to 2000 levels by 2010, 1990 levels by 2020, and 80 percent below 1990 levels by 2050 (Schwarzenegger, 2005). The Bay Area, South Coast and San Joaquin Valley Air Pollution Control District (San Joaquin Valley) have used the 2020 goal as the basis for developing their thresholds.

California Global Warming Solutions Act of 2006 - Assembly Bill 32 (AB 32). Passed in 2006, AB32 set the target of reducing the State’s GHG emissions to 1990 levels by 2020 into law (California Health and Safety Code, 2006). Achieving this target would result in an estimated 30 percent reduction in GHG emissions in the State (CARB, 2008). The law directs the California Air Resources Board (CARB) to adopt rules and regulations to achieve this reduction, which is discussed more under the California Air Resources Board heading in this section. Like Executive Order S-3-05 targets, air districts have drawn from the AB 32 statute to develop GHG thresholds of significance.

California Environmental Quality Act (CEQA). Adopted in 1970, CEQA is a State law that requires public agencies to disclose the environmental effects of discretionary actions and to mitigate the significant adverse impacts associated with those actions to the extent feasible. While CEQA requires the disclosure of a project's contribution to climate change and obligates lead agencies to apply all feasible mitigation if the project's contribution is determined significant, much more effort is needed than CEQA could possibly provide to meet the goals of AB 32 since CEQA only applies to future projects. The harmful "effects of GHG emissions resulting from individual projects are best addressed and mitigated at a programmatic level” through comprehensive planning and the implementation of GHG reduction stategies and adaptation strategies (CNRA, 2009, p. 17).

Under CEQA, agencies are required to analyze and mitigate the effects of GHG emissions. For any given project, public agencies fulfill the roles of lead, responsible, commenting or trustee agency. A lead agency 
is the public agency that has primary discretionary authority for project approval. The lead agency is responsible for analyzing potential environmental impacts, determining the significance of those impacts and if significant, requiring that all feasible mitigation is applied. A responsible agency is an agency that has approval authority for a portion of the project, such as permitting authority. A responsible agency typically provides guidance to the lead agency for addressing effects under its purview.

Commenting agencies are public agencies that have jurisdiction over a particular resource by law, but are not the lead or responsible agency for the project. These agencies review and comment on the adequacy of CEQA documents prepared by the lead agency. Trustee agencies are the Department of Fish and Game, State Lands Commission, the Department of Parks and Recreation, and the University of California, which have statewide jurisdiction over natural resources. Trustee agencies must be notified and consulted if a project may have an adverse impact on one of the natural resources under the jurisdiction of these agencies. Air districts in California typically act as responsible or commenting agencies, but are also sometimes lead agencies for stationary industrial projects. Historically, air districts have adopted thresholds of significance for criteria pollutants and have reviewed CEQA documents for their compliance with air quality standards. Similar to criteria pollutants, air districts are developing GHG thresholds for their internal use as lead agencies and as guidance for other lead agencies to adopt "for use in determining whether a project may have significant environmental effects” (Protect the Historic Amador Waterways v. Amador Water Agency (2004) 116 Cal.App.4th 1099, 1108; CNRA, 2009, p. 85).

SB 97 CEQA: Greenhouse Gas Emissions. Passed in 2007, this law requires the Office of Planning and Research to "prepare, develop, and transmit" amendments to the CEQA Guidelines for the mitigation of greenhouse gas emissions to the Natural Resources Agency by July 1, 2009 (CNRA, 2009, p. 10). The CEQA Guidelines provide detailed guidance for compliance with the requirements of CEQA. This law has further verified that climate change is within the scope of CEQA.

Office of Planning and Research (OPR). Pursuant to SB 97, OPR drafted the CEQA Guidelines Amendments to provide guidance on mitigation for GHG emissions. Prior to transmitting the Guidelines, 
OPR issued a Technical Advisory, CEQA and Climate Change: Addressing Climate Change through California Environmental Quality Act (CEQA) Review, to provide preliminary guidance to lead agencies. In this advisory, OPR tasked the CARB with developing a common statewide methodology for developing GHG thresholds of significance.

In lieu of a common statewide methodology for adopting thresholds, the Technical Advisory outlines a recommended three-step approach for addressing GHG emissions in CEQA documents by 1) identifying GHG emissions, 2) determining significance and 3) mitigating impacts. To identify the GHG emissions, OPR recommends that lead agencies "make a good-faith effort, based on available information, to calculate, model, or estimate” the total GHG emissions from a project (OPR, 2008, p.5). OPR states that although GHG impacts are cumulative in nature, some projects may not "contribute to a significant cumulative impact on the environment” and thus significance should be determined on a project-by-project basis (OPR, 2008, p. 6). The advisory lists examples of GHG reduction measures that have been used by some public agencies for GHG mitigation. Furthermore, OPR recommends that agencies address climate change at the programmatic level and directs CARB to "recommend a method for setting a threshold of significance for GHG emissions” and "identify a range of feasible options, including qualitative and quantitative options” (OPR, 2008, p. 8).

California Natural Resources Agency (CNRA). The CNRA adopted amendments to the CEQA Guidelines on December 30, 2009 "for the mitigation of greenhouse gas emissions or the effects of greenhouse gas emissions” pursuant to SB 97 (CNRA, 2009, 1). The updated CEQA Guidelines contains new guidance specific to adopting thresholds of significance. For more on this new guidance, see Section III, Threshold Types. In accordance with Administrative Procedure Act, the CNRA issued a Final Statement of Reasons for Regulatory Action Amendments to the State CEQA Guidelines Addressing Analysis and Mitigation of Greenhouse Gas Emissions Pursuant to SB97. This accompanying document provides background information, supporting reasoning and responses to all comments regarding the amendments to the State CEQA Guidelines. 
California Air Resources Board (CARB). As required by AB 32, CARB adopted a Scoping Plan in 2008 containing GHG reduction measures for meeting the AB 32 target of reaching 1990 levels by 2020. Some measures contained in the plan include regulating GHG emissions from vehicles, adopting a renewable portfolio standard, implementing a cap and trade mechanism and administering regional transportation reduction targets. Measures from this plan are estimated to reduce statewide land use sectors emissions by 21.1\% leaving local governments responsible for reducing the remaining $2.8 \%$ emissions through efficient land use decisions and measures to reduce emissions from existing sources to meet the $\mathrm{AB} 32$ reduction goal of 23.9\% from the land use driven sectors (BAAQMD, 2010).

Also in 2008, at the direction of OPR, CARB embarked on an effort to develop a common statewide methodology for developing thresholds of significance and propose statewide interim thresholds. Although no formal guidance on thresholds has been adopted by CARB and this process seems to be indefinitely stalled, the agency released a Preliminary Draft Staff Proposal: Recommended Approaches for Setting Interim Significance Thresholds for Greenhouse Gases under CEQA that provides detailed methods for developing thresholds of significance. For more on this document, see Section III, Threshold Types.

In 2009, CARB's Mandatory Reporting Rule took effect which requires certain large stationary sources that emit over 25,000 tons of CO2 to report their annual emissions to "better understand these sources to develop the proposed emissions reduction measures outlined in this plan” (CARB, 2008b, p. 108). This reporting limit should not be confused with thresholds set by lead agencies for CEQA purposes as CARB's reporting threshold "does not address the level at which environmental harm may occur, and does not satisfy a lead agency’s duties under CEQA” (CNRA, 2009, p. 26).

SB 375. Passed in 2008, SB 375 requires metropolitan planning organizations (MPOs) to develop sustainable communities strategies (SCSs) in regional transportation plans (RTPs) that integrate transportation, housing and land use planning to meet regional GHG targets set by CARB. A CARB approved SCS is a type of GHG reduction plan that provides for streamlining under CEQA. Transit priority projects that are consistent with an approved SCS are exempt from addressing "(1) growth inducing 
impacts; or (2) any project specific or cumulative impacts from cars and light-duty truck trips generated by the project on global warming or the regional transportation network” (California Public Resources Code $\S$ 21159.28 (a)) In addition, an environmental impact report (EIR) for such projects is not required to include "a reduced residential density alternative to address the effects of car and light-duty truck trips generated by the project (California Public Resources Code § 21159.28 (b)). While MPOs are required to produce these plans, there is no enforcement of cities and counties to implement the plans.

Office of the Attorney General. The California Office of the Attorney General (AG) has pursued actions to enforce lead agencies to comply with goals set in AB 32 in planning and CEQA documents. The AG has filed comment letters, litigation and has reached agreements to resolve CEQA disputes with local governments regarding climate change. The AG has a webpage devoted to global warming at www.ag.ca.gov/globalwarming that provides information to cities, counties and regional agencies on CEQA and climate change, past settlements, funding sources and other topics (AG, 2010). The AG has submitted comment letters critiquing the thresholds of significance adopted by air districts in California. For more on the AG's comment letters, see Section III, Threshold Types.

Court Rulings. Since the adoption of AB 32, the courts have issued hundreds of decisions regarding the legitimacy of addressing GHG emissions under CEQA, NEPA, the CAA, and other State laws. Below are highlights from select cases pertinent to the need for and adequacy of GHG analysis in CEQA documents related to thresholds and significance findings. In the following cases, the courts decided that CEQA requires consideration of GHG emissions, and the lack of a GHG significance threshold does not exempt projects from analyzing and determining the significance of a project's emissions. Additionally, courts have advised agencies to consult guidance by OPR and CAPCOA for methods for determining the significance of a project’s environmental impacts.

California v. County of San Bernardino: In the first lawsuit filed by the AG related to the adequacy of addressing climate change under CEQA, the AG claimed that the County of San Bernardino County failed to analyze GHG emissions in their general plan amendment. The County asserted that no methodology 
existed for determining the significance of the environmental effects of the GHG emissions attributed to the general plan update. The lawsuit was settled out of court with the County agreeing to include a goal in their general plan update to reduce GHG emissions attributable to the plan and to prepare a GHG emissions reduction plan. This plan is required to include a baseline and 1990 GHG emissions inventory with projections to 2020, target reductions and measures to achieve this target (California v. County of San Bernardino, 2007).

City of Stockton Agreement: In a similar settlement agreement, the City of Stockton agreed to prepare a GHG reduction plan after it failed to include enforceable mitigation measures to address the GHG emission impacts attributable to the general plan (City of Stockton, 2008). Specifically, the GHG reduction plan was required to discourage sprawl and promote infill development, public transit and energy-efficient buildings be (City of Stockton, 2010).

Center for Biological Diversity (CBD) v. City of Desert Hot Springs: A California Superior Court invalidated an EIR for a luxury resort partially on the grounds it "failed to make a meaningful attempt to determine the project's effect on global warming before determining that any attempt would be speculative” (CBD v. City of Desert Hot Springs, 2008, p. 2). The court stated that the EIR “failed to meet CEQA's requirements" citing the AB 32 goal adopted by the Legislature and OPR's direction through SB 97 to develop CEQA guidelines specific to GHG emissions (CBD v. City of Desert Hot Springs, 2008, p. 1).

Environmental Council of Sacramento v. California Department of Transportation (Caltrans): The Sacramento County Superior Court found that an EIR submitted by Caltrans was not exempt from GHG analysis under SB $375^{1}$ because the EIR was submitted prior to the legislation becoming effective. More applicable to the topic of this paper, Caltrans' argument that it was impossible to quantify the project's GHG emissions or determine their significance because there was not an adopted GHG threshold was rejected by the court (Environmental Council of Sacramento v. Caltrans, 2008).

\footnotetext{
${ }^{1}$ Public Res. Code § 21097(a)
} 
Center for Biological Diversity (CBD) v. Town of Yucca Valley: The County of San Bernardino Superior Court required the Town of Yucca Valley to recirculate the air quality portion of an EIR for a proposed Wal-Mart Supercenter on the grounds that it failed to adequately address GHG emissions for the project. Specifically the court stated that the EIR failed to consider the entire GHG output of the project as required by the OPR and displayed "abuse of discretion” by ignoring CAPCOA's guidance on attaining AB 32 targets in their discussion of cumulative impacts (CBD v. Town of Yucca Valley, 2009, p.3). Furthermore, although the Town's approach to rely on the Climate Action Taskforce (CAT) report to determine significance did not violate CEQA, they failed to provide substantial evidence that the project complied with all applicable CAT strategies.

Communities for a Better Environment (CBE) v. City of Richmond: In the first California appellate court case on GHG analysis in an EIR, the court ruled that a mitigation measure in the EIR for Chevron's Energy and Hydrogen Renewal Project unlawfully deferred mitigation by requiring that a plan to achieve complete reduction of GHG emissions be submitted within one year of project approval. This deferral undermines CEQA's goal of full disclosure and informed decision making. Additionally, the final EIR stated that the increase in GHG emissions by the project did not constitute a significant impact. The court cited that AB32 recognizes that "global warming poses a serious threat to the economic well-being, public health, natural resources, and the environment of California” (Health \& Safety Code, § 38501 (a)) and suggested consulting CAPCOA's white paper for “different approaches for making a determination concerning whether a project's greenhouse gas emissions would be significant or less-than-significant” (CBE v. City of Richmond, 2010, p.20).

California Air Pollution Control Officers Association (CAPCOA). CAPCOA is an association of the thirty-five Air Pollution Control Officers representing their local air district throughout California. As an association of air pollution experts, CAPCOA has issued several white papers on climate change including CEQA \& Climate Change: Evaluating and Addressing Greenhouse Gas Emissions from Projects Subject in 2008, Model Policies for Greenhouse Gases in General Plans: A Resource for Local Government to Incorporate General Plan Policies to Reduce Greenhouse Gas Emissions in 2009, and Quantifying 
Greenhouse Gas Mitigation Measures: A Resource for Local Government to Assess Emission Reductions from Greenhouse Gas Mitigation Measures in 2010. The first document has been widely cited by the courts as "scientific and factual analysis regarding attainment of California GHG emission targets" (CBD v. Town of Yucca Valley, 2009, p.3). It provides “policy choices, analytical tools, and mitigation strategies” for addressing GHG emissions under CEQA (CAPCOA, 2008, p.1). These documents provide air districts and other agencies with options for developing GHG thresholds of significance.

California Air Districts. There are thirty-five air quality districts in California organized by air basins. These agencies monitor and enforce air quality standards and provide planning and outreach to meet Federal and State health based air quality standards. Air districts can act as lead, responsible or reviewing agencies under CEQA and have historically provided expert analysis to lead agencies regarding air quality thresholds. While CEQA does not require that lead agencies use thresholds developed by air districts, “Appendix G of the State CEQA Guidelines expressly encourages lead agencies to rely on thresholds established by local air quality management districts” (CNRA, 2009, p.30). Many cities and counties are turning to their local air districts for guidance on setting GHG emission thresholds. However, unlike other air district CEQA thresholds that are adopted to assist the agency's efforts to obtain and maintain the health-based air quality standards set by the U.S. EPA and CARB, no limits have been established by these agencies for GHG emissions. Despite the lack of federal and state adopted ambient air quality standards for GHG emissions, air districts are developing their own thresholds for a number of reasons including to streamline the CEQA review process to reduce time an expense required to review individual projects, provide greater certainty for lead agencies and project proponents and to ensure more consistency in how GHG emissions are assessed in CEQA documents.

Cities and Counties. California cities and counties have jurisdiction over land use decisions that can impact GHG emission levels. Many cities and counties are taking measures to inventory GHG emissions in their jurisdictions and are developing climate action plans (CAP) or other GHG reduction plans to meet GHG reduction goals set at the local level. These plans can provide streamlining review of GHG emissions under 
CEQA. Section 15183.5 (b) of the CEQA provides criteria that these plans must meet to allow tiering and streamlining of GHG analysis for specific projects under CEQA. To be used for this purpose, plans should:

“(A) Quantify greenhouse gas emissions, both existing and projected over a specified time period, resulting from activities within a defined geographic area;

(B) Establish a level, based on substantial evidence, below which the contribution to greenhouse gas emissions from activities covered by the plan would not be cumulatively considerable;

(C) Identify and analyze the greenhouse gas emissions resulting from specific actions or categories of actions anticipated within the geographic area;

(D) Specify measures or a group of measures, including performance standards, that substantial evidence demonstrates, if implemented on a project-by-project basis, would collectively achieve the specified emissions level;

(E) Establish a mechanism to monitor the plan's progress toward achieving the level and to require amendments if the plan is not achieving specified levels;

(F) Be adopted in a public process following environmental review” (State CEQA Guidelines, Section 15183.5 (b).

In the interim, while these plans are being developed and implemented, lead agencies are encouraged to adopt thresholds of significance that are supported by substantial evidence and developed through a public process for use in determining the significance of the environmental effects of a project (CNRA, 2009). 


\section{THRESHOLDS OF SIGNIFICANCE FOR GHG EMISSION - TYPES AND APPROACHES}

As seen in the previous section, there are numerous efforts underway at all levels of government to address the impacts of global changes to the climate. Addressing GHG emissions through CEQA is just one small piece of the puzzle to help reduce harmful GHG emissions that contribute to climate change. Since CEQA addresses future discretionary land use projects, it provides a useful tool for assessing future emissions to help stabilize or reduce GHG emissions, particularly in the interim before programmatic approaches, such as local and statewide plans for reducing climate change, are fully implemented.

Since the passage of AB 32 and SB 97, California lead agencies have been challenged with the task of determining the significance of climate change-related impacts from discretionary projects and, if presumed significant, requiring that all feasible mitigation be applied to substantially reduce the significance of the impact (CARB, 2008). However, determining what level of greenhouse gas emissions is significant can be challenging, especially for a pollutant like GHG emissions where the impacts are global in nature and the statewide targets are less than is currently being emitted. Establishing thresholds of significance can assist lead agencies in making this determination.

To aid public agencies in this effort, guidance documents on approaches for developing thresholds have been written by several State agencies and air quality experts. Three of the primary guidance documents on developing thresholds are CNRA's Final Statement of Reasons for the CEQA Guidelines Amendments, CAPCOA's white paper on CEQA and Climate Change, and CARB's Preliminary Staff Proposal on Recommended Approaches for Setting Significance Thresholds for Greenhouse Gases under the CEQA.

Additionally, although the Attorney General’s Office has not developed formal guidance for lead agencies on thresholds of significance, they have submitted formal comment letters to lead agencies on their approaches. These comments can be used as general guidance for other lead agencies as they move forward in developing thresholds. Together, all of these documents have helped frame the discussion on approaches for developing GHG thresholds of significance. 
The following discussion covers the key guidance on thresholds that the CEQA Guidelines provide, including guidance from the 2010 amendments and summarizes the approaches for developing thresholds of significance presented in the CAPCOA and CARB documents. This discussion is intended to provide an overview of previous public discussion that has taken place about different threshold approaches and provide a common platform for understanding the general approaches that have been considered at a conceptual level. This section provides the context for the approaches that air districts have actually taken or are considering, which will be addressed in the Section IV, Results.

\section{What are thresholds of significance?}

Thresholds aid lead agencies in their determination of significant environmental impacts under CEQA by establishing quantitative, qualitative, or performance-based standards for what level of emissions "will normally be determined to be significant by the agency” (State CEQA Guidelines, § 15064.7(a); CNRA, 2009, p.84). While nothing in CEQA requires that lead agencies adopt thresholds of significance, the CEQA Guidelines specifically encourage public agencies “to develop and publish thresholds of significance” for use in determining significance (State CEQA Guidelines, § 15064.7). Any threshold adopted for use in environmental review must be formally adopted through a "public review process and be supported by substantial evidence” (State CEQA Guidelines, § 15064.7). Additionally, the 2010 CEQA Guidelines Amendments Update provides new guidance on thresholds of significance, clarifying that lead agencies may consider adopting thresholds of significance developed "by other public agencies or recommended by experts, provided the decision of the lead agency to adopt such thresholds is supported by substantial evidence" (State CEQA Guidelines § 1506.4). Furthermore, Appendix G of the "State CEQA Guidelines expressly encourages lead agencies to rely on thresholds established by local air quality management districts” (CNRA, 2009, p.39). To develop GHG thresholds of significance, air districts can pull from "existing environmental standards, such as other statutes or regulations” (State CEQA Guidelines, § 15064.7; CNRA, 2009, p. 85). Regardless of how a threshold is developed, lead agencies should carefully consider the applicability of adopted thresholds to a project because even if a project complies with an adopted threshold, CEQA's fair argument standard requires lead agencies to prepare an EIR if "substantial evidence” supports a "fair 
argument” that there may be significant impacts resulting from the project (Mejia v. City of Los Angeles (2005) 130 Cal.App.4th 322, 342.; CNRA, 2009, p.26, 85).

\section{Guidance on Setting Thresholds for GHG Emissions}

\section{CAPCOA's CEQA \& Climate Change: Evaluating and Addressing Greenhouse Gas Emissions from Projects Subject to CEQA}

In 2008, CAPCOA authored a white paper on CEQA and Climate Change that has since been cited as an authoritative source by California courts on "different approaches for making a determination whether a project‘s greenhouse gas emissions would be significant or less-than-significant” (CBE v. City of Richmond, 2010, p. 20). As a reputable source, lead agencies could use concepts in the white paper in developing their thresholds (CNRA, 2009). In the white paper, CAPCOA reviews approaches for developing thresholds for GHG emissions from industrial, commercial/residential, construction sources and plans. However, any threshold considered by a lead agency "must be supported with substantial evidence, and must be adopted through a public process” to ensure its adequacy (State CEQA Guidelines, § 15064.7(b); CNRA, 2009, p. 30). Although they do not make any clear recommendations, CAPCOA considers three general types of thresholds in the document: the no threshold, zero emissions threshold and non-zero threshold, and provides an evaluation of the effectiveness, feasibility, advantages and disadvantages of the non-zero threshold approaches presented.

In the white paper, CAPCOA first highlights the shortcomings of CEQA analysis without an adopted threshold, or the "no threshold" situation. CAPCOA emphasizes that the absence of a GHG threshold does not alleviate lead agencies from making a significance determination (CAPCOA, 2008). In fact, the amount of work required by agencies will likely increase if there is no adopted threshold to aid them in making significance determinations (CAPCOA, 2008). This approach can also lead to inconsistencies in how an agency addresses GHG emissions for different projects under CEQA. The uncertainty that this creates can be problematic for project applicants since they cannot easily evaluate if their project will likely be subject to CEQA. While this option is not preferred because of the increased workload and uncertainties it creates, 
many lead agencies are operating under this condition as a default since they do not yet have adopted thresholds. In lieu of an agency having adopted thresholds to aid them in their significance determination, agencies can follow OPR's recommended approach for evaluating GHG emissions under CEQA outlined in its Technical Advisory and guidance from the 2009 CEQA Guidelines Amendments.

The second threshold type is the "zero emissions threshold." Setting a threshold at zero means that any net increase in emissions would be considered significant, thus placing "all discretionary projects under the CEQA microscope” (CAPCOA, 2008, p.3). This approach would undoubtedly increase the workload for responsible and lead agencies to an impractical level since nearly all discretionary projects would be considered significant and require an EIR. Because of the increased burden this would place on agencies and project applicants, it would likely be politically unfeasible to pass such a stringent threshold. Moreover, lead agencies are not required to adopt a zero emissions threshold because "GHG impacts are exclusively cumulative impacts” (CAPCOA, 2008, p. 35) and as such, "one [additional] molecule” is not considered to be a significant contribution to the climate change (CBE, supra, 103 Cal.App.4th at 120; CNRA, p. 25, 85). Instead, lead agencies are required to determine whether the cumulative impact is significant and whether the proposed project’s incremental effects are cumulatively considerable (CBE, supra, 103 Cal.App.4th at 120; CRNA, 2009). Since a zero emissions threshold seems inconsistent with the spirit of CEQA and is politically impractical, it has been dismissed by most agencies as a viable option.

The third general type of threshold considered is the "non-zero emissions threshold.” Non-zero emissions thresholds are thresholds that are set at a level higher than zero, with a higher threshold representing a less stringent threshold. CAPCOA identifies two approaches for setting non-zero thresholds, the "statute and executive order approach" and the "tiered approach.” A discussion of possible options for implementing these approaches is included, along with the foreseeable pros and cons of each method.

The statute and executive order approaches use GHG emission reduction targets from existing statewide regulations (AB 32 and S-3-05) to derive local thresholds. CAPCOA identifies four statute and executive order approaches: 1) AB 32/S-3-05 Derived Uniform Percentage-Based Reduction, 2) Uniform Percentage- 
Based (e.g.50\%) Reduction for New Development, 3) Uniform Percentage-Based Reduction by Economic Sector, and 4) Uniform Percentage-Based Reduction by Region. The first method uniformly applies the corresponding estimated reductions needed to reach the AB 32/S-3-05 reduction goals to all discretionary projects. Using this method, GHG emissions from a project must be reduced by 33 percent (corresponding AB32 reduction) or 90\% (corresponding S-3-05 reduction) from the business-as usual scenario (BAU) (ie. "emissions that would have occurred in the absence of the mandated reductions") (CAPCOA, 2008, p.32). The second method simply requires a 50\% reduction from BAU to all discretionary projects. The third approach would apply uniform percentage reductions separately for each economic sector (ie. residential, commercial, industrial, etc.). The last approach presented requires projects to demonstrate their compliance with regionally adopted plans that aim to reduce regional emissions to 1990 levels by 2020 and $80 \%$ less by 2050 to be determined not significant. While the statute and executive order approaches presented distribute the burden uniformly to all discretionary projects, the ambiguity on how to determine BAU for each project and lack of a clear threshold leaves considerable uncertainty for project proponents and agencies.

The tiered approach allows for an agency to develop multiple acceptable methods to aid in its significance determination. This approach includes a sequence of tiers that include different methodologies for aiding in a significance determination. At each tier, if the project does not meet the criteria for being less than significant, the project is then evaluated at the subsequent tier until it is determined that the project either complies with one of the tiers, in which it would generally be considered less than significant, or it is determined that the project does not meet the criteria for any of the tiers, in which the project would be assumed to have a significant impact. This approach recognizes that different project characteristics, such as size, location and type, influence the ability to apply different feasible mitigation to meaningfully reduce overall GHG emissions from new discretionary projects. The tiered approach provides greater certainty to project applicants and agencies and provides more flexibility by recognizing the validity of using various approaches for determining significance for different types of projects.

Under this approach, the first tier generally would include compliance with a certified climate action plan (CAP) thresholds or other methodologies (see Section II, Regulatory Framework for more information on 
CAPs). The OPR, CNRA and AG office have all expressed that "the effects of GHG emissions resulting from individual projects are best addressed and mitigated at a programmatic level” (CNRA, 2009, 17). However, as of the date of this document, the only example of a GHG reduction plan in California that allows for projects to tier off of them for CEQA streamlining for GHG emissions is the City of San Carlos Climate Action Plan. Until such plans as SCS or certified CAPs are developed, projects must meet the criteria in subsequent tiers to generally be assumed less than significant.

Following compliance with a GHG reduction plan, the remaining tiers could require compliance with various thresholds and mitigation to be generally considered less than significant. The CAPCOA white paper covers seven potential threshold options that could be included in subsequent tiers:

1) Zero First Tier Tiered Threshold: A zero threshold could be listed as a first tier with accompanying feasible mitigation to meet this tier. While this method would capture all GHG emissions, as stated above, a zero threshold is not required under CEQA because , there is no 'one molecule' rule in CEQA” (CBE, supra, 103 Cal.App.4th at 120; CRNA, 2009, p. 25, 85).

2) Quantitative Thresholds Based on Market Capture: Another option is to use a threshold designed to capture approximately $90 \%$ of future residential and commercial development. Using a small sample size of projects from four diverse cities, a threshold of 900 MT was derived. This threshold level corresponds to 50 residential units and 30,000 square feet of commercial space, which represents $90 \%$ of all future discretionary projects from these cities. This threshold would ensure that most emissions are captured, while excluding smaller projects from burdensome CEQA requirements.

3) CARB Reporting Threshold: For industrial projects, the CARB reporting threshold of 25,000 MT/yr or the CARB Market Advisory Committee’s recommendation for a cap and trade program to cover sources emitting $10,000 \mathrm{MT} / \mathrm{yr}$ threshold are listed as potential options. It is estimated that the 25,000 MT/yr threshold would capture 94\% of all GHG emissions from stationary sources. Therefore, a 10,000 MT threshold should capture more than $90 \%$ of emissions. However, the CNRA states in its supporting document for the CEQA 
Guidelines Amendments that the CARB reporting threshold "reflects a policy decision regarding regulation by the CARB, but does not address the level at which environmental harm may occur, and does not satisfy a lead agency’s duties under CEQA related to review of projects which may result in significant adverse environmental impacts" (CNRA, 2009, p.26). As with any threshold, an agency must provide "substantial evidence” to adequately justify the use of one of these thresholds (State CEQA Guidelines, § 15064.7(b)).

4) Regulated Emissions Inventory Capture: CAPCOA also suggests that an agency could use the established thresholds for the ozone precursors of ROG and NOx to develop analogous thresholds for GHG emissions. To do this, an air district would find the percent of the ozone precursor emissions that the NOx/ROG threshold captures of the total regional ROG/NOx emissions inventory and apply that percent to the statewide GHG inventory to derive an analogous threshold for GHG emissions. However, this approach would likely capture less GHG emissions than most other methods explored.

5) Unit-Based Thresholds Based on Market Capture: This option follows a similar methodology of the Quantitative Thresholds Based on Market Capture, but considers commercial projects by type and size individually, realizing that the emissions from different types of commercial projects with similar sizes can vary greatly based on project type. This threshold would have similar strengths and weaknesses as the other market capture thresholds option.

6) Projects of Statewide, Regional, or Area-wide Significance: The sixth threshold option considered uses the definitions of "projects with statewide, regional or area-wide significance" from the CEQA Guidelines to develop a set of tiered thresholds for these projects. While this approach does not provide the highest GHG emissions reduction effectiveness, it is technically and economically feasible and uses an existing framework within CEQA (CAPCOA, 2008, p.48). However, this approach may not be legally defensible because the thresholds are not based on substantial evidence specific to the impacts of GHG emissions.

7) Efficiency-Based Thresholds: The last threshold option considered is the efficiency-based threshold. This threshold would be based on an efficiency measurement such as GHG emissions per capita, or per 
employment or some combination for plans and GHG emissions per dwelling unit, or per square foot of commercial space or some combination for projects. CAPCOA does not provide an evaluation of this approach because at the time that this document was written, the detailed GHG emission inventory data needed to review this option was not available. For a more detailed explanation of these approaches, see pages 31-57 of the CEQA and Climate Change white paper (CAPCOA, 2010).

The concepts presented in the white paper represent the first documented attempt to develop potential methodologies for agencies to use in developing their GHG thresholds. In the same year that the CAPCOA white paper was published, the CARB, at the direction of OPR, began an effort to develop statewide guidance. While CARB has not adopted a threshold, the work that was done provides another useful methodology to for agencies to consider in developing GHG thresholds.

\section{CARB's Recommended Approaches for Setting Interim Significance Thresholds for Greenhouse Gases under the California Environmental Quality Act}

In 2008, CARB developed recommended approaches for setting interim GHG thresholds for lead agencies. The approaches explained in the Preliminary Draft Staff Proposal were intended to provide guidance for lead agencies in the interim until programmatic approaches are adopted and fully implemented. CARB prescribed using different methods to develop different thresholds of significance for the industrial sector and residential and commercial sectors. For both approaches, CARB recommends using a tiered approach, similar to what was described above from CAPCOA's white paper. While none of these approaches have been finalized or adopted by CARB, they provide a more detailed look at many of the approaches outlined in the CAPCOA white paper.

For the industrial threshold, CARB recommends a three-tiered approach that uses both a quantitative threshold and performance standards. The first tier considers a project less than significant if the project is “exempt under existing statutory or categorical exemptions” (CARB, 2008a, p.7). If a project is not exempt, it must meet CARB's interim performance standards for construction and transportation-related GHG emissions 
and a 7,000 MT CO2e /yr threshold to be presumed less than significant. If a project cannot feasibly meet this second tier, the project is presumed to be significant and an EIR must be prepared.

CARB derived the 7,000 MT threshold for industrial sources by applying the estimated proportion of process losses, purchased electricity and water use and wastewater treatment for industrial facilities to an estimated 4,600 MTCO2e/yr emissions that are associated with a natural gas boiler input capacity benchmark of 10 MMBtu/hr. However, some comments argued that the threshold should be based on California actual GHG emission data on boilers instead of estimated emissions associated with national data on boiler capacity as CARB had done. In addition, some comments indicated that a threshold of 10,000 MT should be adequate because this higher threshold would still capture at least $90 \%$ of emissions as previous analysis by CARB has shown (Baird, 2009). Additionally, some comments stated that CARB may have made a calculation error that resulted in a lower threshold than this methodology should have produced (Morrow, 2008). Since CARB has not continued in their effort to provide interim guidance on GHG thresholds, none of these comments have been formally addressed.

CARB's recommended interim approach for residential and commercial projects includes four tiers. The first tier considers if the project is exempt "under existing statutory or categorical exemptions" (CARB, 2008a, p.11). In the second tier, projects that comply with programmatic approaches to address GHG emissions, such as a certified CAP or SCS, are presumed to have less than significant impacts related to climate change. The third tier requires projects to meet minimum performance standards for construction, energy, water use, waste and transportation-related GHG emissions, in addition to meeting an undefined threshold. CARB did not provide a value or methodology for this potential threshold in this draft and has not continued the work towards this end. In the final tier, if a project does not meet any of the previous tiers, the project is presumed to be significant and an EIR must be prepared. While CARB did not complete its recommendations for setting interim significance thresholds for GHG emissions, the comments and ideas that emerged through the development of the draft staff proposal helped to further the discussion about approaches for setting GHG thresholds of significance. 
In practice, several of the approaches presented by CAPCOA and CARB have been used on their own, in combination or have been adapted by air districts throughout California to develop local GHG thresholds of significance. The discussions that took place during the development of these documents laid the foundation for the approaches that have been seen in practice. Although these documents were written in 2008, they still provide relevant discussion on possible approaches that agencies can use to developed thresholds.

\section{Comment Letters from the Office of the Attorney General}

The opinions of the Attorney General on the GHG thresholds developed by the San Joaquin Valley Unified Air Pollution Control District (San Joaquin Valley) and Bay Area Air Quality Management District (Bay Area) provide useful guidance for developing thresholds. As part of the public review process, the AG submitted comment letters to the San Joaquin Valley and Bay Area on the thresholds developed by each district. The general comments from these letters can be used as a basic checklist of requirements that should be met when developing thresholds. The following questions are direct questions or rephrased statements from the Attorney General’s comment letters:

\section{From the San Joaquin Valley Unified Air Pollution Control District Comment Letter:}

1. "What defined, relevant environmental objective is the threshold designed to meet, and what evidence supports selection of that objective?”

2. "What is the evidence that adopting the threshold will meet this objective?”

3. "How does the threshold take into account the presumptive need for new development to be more GHG-efficient than existing development?”

4. "Will the threshold routinely require new projects to consider mitigation beyond what is already required by law?”

5. "Will operation of the threshold allow projects with large total GHG emissions to avoid environmental review? What evidence supports such a result?”

6. “Will the threshold benefit lead agencies in their determinations of significance?” (Brown \& Sullivan, 2009, p. 2, 3, \& 4). 
From the Bay Area Air Quality Management District Comment Letter:

7. Does "the stringency of the thresholds match the seriousness of the problem"?

8. Do "the thresholds minimize the potential for 'gaming"”?

9. Do "the thresholds recognize that CEQA is more than just a mechanism to enforce other laws and regulations”?

10. "How [will] the thresholds serve not only interim, but longer-term climate objectives”?

11. Does the air district intend to "work with... cities and counties to ensure that the efficiencybased threshold fulfills its purpose to encourage smart growth”?

12. Is there "an express[ed] commitment by the agency to monitor the thresholds over time and to adjust them if necessary”? (Brown \& Sullivan, p. 2, 3).

While this is not an exhaustive list of what agencies should consider when developing GHG thresholds of significance, it provides a starting place to frame their decisions. The comments from the Attorney General, along with the threshold guidance provided by the updated CEQA Guidelines, CAPCOA and CARB, provide agencies with a basic understanding of the generally accepted options for developing GHG thresholds of significance. As seen in the next section, air districts have used this guidance as a foundation for developing GHG thresholds and are continuing to adapt and build upon the guidance outlined above. 


\section{RESEARCH METHOD}

This research seeks to define the current state of the practice for developing GHG thresholds of significance by air districts and to identify any emerging trends. In fulfilling these objectives, this research provides a snapshot in time of what direction regional air pollution agencies are taking and reveals the motivation driving their actions. Understanding the types of guidance that regional air districts have proposed, adopted or are considering may give a more comprehensive picture of how GHG emissions will be addressed in CEQA documents statewide. The following explains the data collection goals, research sample, instrument, and data analysis used for this research.

\section{Data Collection Goals}

Since the State of California has not developed a single methodology for developing GHG thresholds of significance and has not adopted statewide thresholds of significance, in some cases, air districts are undergoing their own individual processes to develop GHG thresholds. However, it is unclear what the state of the practice is for developing GHG thresholds because the information on the actions that air districts have taken or are considering taking exists in numerous locations. For air districts that have adopted thresholds, there is no document that compares all the adopted thresholds, along with the approaches, and implementation and processes used in their development. Furthermore, no document exists that explains the thought processes behind what approaches air districts are considering that do not have adopted thresholds. This research effort seeks to:

- define the state of the practice for developing GHG thresholds of significance, and

- $\quad$ provide insight into emerging trends.

\section{Research Sample}

Two sets of data are needed to explain the thought processes behind what guidance air districts are adopting, proposing or considering, individuals were selected through purposive sampling, which is a nonprobabilistic sampling technique, to participate in a study. These two data sources are interviews with air districts that have adopted or proposed thresholds, State agencies and experts on the subject, and surveys 
with air districts that do not have adopted thresholds. Participants of the study were chosen because they were fundamentally involved with the development of GHG thresholds or other related guidance. Three separate categories of experts were identified for this research: employees of air districts in California; employees of State agencies; and consultants that are considered experts on this issue. All participants were selected for their expert knowledge or a high level of involvement with their agencies on the topic. In total, twenty-seven individuals were selected to participate in the study.

While lead agencies can develop their own thresholds apart from air districts, this study focuses on air districts because CEQA specifically encourages lead agencies to adopt guidance developed by air districts for air quality-related issues. As regional agencies with the sole responsibility for providing comprehensive air pollution control, air districts are regarded as experts on issues related to air quality. For these reasons, as air districts continue to develop guidance, it is reasonable to assume that lead agencies will follow suit. However, not all air districts were contacted to participate in the research. Some air districts are much further along in developing guidance than others. For the purposes of this research, only the regions that have demonstrated initiative on this topic (through developing documents, working with other agencies or posting information on their websites) were consulted. In addition, air districts were selected based on whether or not they typically review CEQA projects, assuming that air districts that review CEQA projects are more likely to develop thresholds. Through this selection process, 18 of 35 air districts were identified and contacted to participate in the study. The individual that was identified to participate in the study from each air district was selected based on their position as the air district Planning Manager or other employee that was directly involved with developing or considering threshold options.

State agencies that were selected to participate in the study were identified based on their involvement with promulgating statewide climate change policy, specifically relating to GHG thresholds. Three State agencies were identified to contact for this study. An individual from each of these agencies was selected to be contacted based on their direct involvement with the subject matter. In a similar manner, four experts in the field were identified to participate in the study. These individuals were selected based on their involvement with consulting air districts on threshold approaches or their involvement through commenting 
on adopted or proposed approaches. In addition to specifically identifying participants, snowball sampling, in which participants are identified through suggestions from other interviewees, was used to locate additional participants that were known by contacted participants to be highly involved on this topic. These individuals were contacted based on the recommendations of other participants. Two additional individuals were added to the sample through this technique, one with a State agency and one that is considered an expert on the topic.

\section{Instrument/Procedures}

Two general sets of questions were developed to administer to participants of the study. Since air districts are at different stages in the process of developing thresholds, it was necessary to develop two separate sets of questions - one set for three air districts that have adopted or proposed thresholds and another set of questions for air districts that have not adopted or proposed thresholds. For all participants, forms were developed to request consent from individuals to participate in the study and to ensure the anonymity of the individual, but not their organizational affiliation.

Individuals from the three air districts that have adopted or proposed thresholds were asked to participate in phone interviews. Phone interviews were chosen as the preferred method to administer the open-ended questions because the questions require lengthy and complex responses and because this format allows for immediate follow-up questions to be asked. The list of questions that were compiled for these air districts included questions on what thresholds were proposed or adopted, which approaches or methods were used to determine appropriate values for thresholds, and what implementation and development processes were employed in creating the thresholds (see Appendix A). Where available, air district documents such as meeting minutes, presentations and CEQA handbooks specifying proposed or adopted GHG thresholds were reviewed prior to the interviews. Furthermore, comment letters from the AG and special interest groups provided additional expert opinions on these different approaches. Reviewing these documents helped to tailor the general list of questions based on the participant. The interviews sought to supplement the information gathered from the documents and provide more depth to questions that could not be answered through documents alone. 
For the remaining fifteen air districts that were identified to participate in the study that do not have adopted or proposed thresholds, a self-administered survey was developed for participants to receive via email to complete on their own. Since little information is available on what threshold guidance these districts plan to provide or if they plan to provide guidance at all, these groups did not lend themselves to in-depth interviews. Instead, an email survey is the ideal instrument to use for the air districts that do not have adopted or proposed guidance because important information can be gained from the survey responses without the amount of time required to conduct a phone interview. The surveys included 12 open-ended questions and one multiple-choice question to gain a general understanding of the approaches these districts are considering, their involvement in developing thresholds guidance and climate change-related planning, and their main challenges and requests for assistance (see Appendix B). The open-ended format of the questions was necessary because there were too many possible responses to the questions being asked to use any other format, such as multiple-choice.

State agencies and other identified experts that have produced public documents on this topic were selected for phone interviews. Questions developed for these groups generally followed the list of questions developed for air districts with adopted thresholds, but were tailored based on the participant. Consent forms developed for phone interview participants specified the request for consent to allow voice recording so that the interviews could be transcribed for accuracy. Interviews for these groups were concluded once a sufficient level of saturation on the issue was satisfied.

\section{Data Analysis}

Data collected from the interviews and survey responses were analyzed using different approaches. For the phone interviews, the voice recordings and written notes were transcribed. Based on this data and information from a literature review of published and informal documents from organizations from which the participants were drawn, a matrix was constructed that allowed for direct comparison between organizations. For the matrix developed, each column category represents the responses from a particular air district, while the row categories were development based on the central tendencies (or common 
themes) that were drawn from the interview responses. The contents of each cell in the matrix illustrates the ranges of responses and the central tendency (Cole, 1994). The matrix was developed to communicate the common themes and to examine the relationships between the different responses in context. In this way, expected and unexpected relations were also more easily identified (Cole, 1994).

For the survey responses, all the responses were read and organized into an Excel spreadsheet. In reading through the responses, common categories were identified. The data was then reduced by coding the range of responses into these categories (Miles \& Huberman, 1994). Once data was grouped into these categories, common themes in the responses were identified. These common themes identified through this process are presented in a discussion in Section V, Results. 


\section{RESULTS}

To establish the state of the practice for GHG threshold development by air districts, data was collected from the interview and surveys conducted with air districts, State agencies and field experts. A total of seventeen of the identified twenty-eight individuals participated in the study, for a $61 \%$ response rate. Twelve of the eighteen air districts agreed to participate in the study, for a $66 \%$ response rate. Of these participants, three participated in phone interviews and nine air districts completed surveys. Some districts declined to respond to survey questions at the advice of district legal counsel. In addition to these surveys and interviews, phone interviews were conducted with individuals from three State agencies and two environmental consultants, for a $75 \%$ and $40 \%$ response rate, respectively. All phone interviews typically lasted about 1 hour. In some cases, a follow-up interview was conducted for an additional hour if more information was needed that could not be covered in the first hour. The data from these surveys and interviews produced two separate sets of results - one for the districts that have adopted thresholds and one for those that have not. The results are organized in the following ways: 1) a comparison matrix of the approaches taken by the three districts that have adopted thresholds and 2) grouping the common themes (considerations, concerns, challenges, etc.) that arose from responses from air districts that have not adopted thresholds. Together, these two sets of results provide a snapshot of how air districts are responding to requests for guidance about GHG emissions.

\section{Adopted or Proposed GHG Thresholds of Significance by California Air Districts}

Three air districts in California have adopted thresholds for use by the air districts as lead agencies or for the potential adoption and use by other lead agencies in their jurisdiction for land use projects. These three air districts include the Bay Area Air Quality Management District (Bay Area Air), the South Coast Air Quality Management District (South Coast) and the San Joaquin Valley Air Pollution Control District (San Joaquin Valley). As shown in Table 1, these three air districts are very different in terms of location, size and population. 


\begin{tabular}{|c|c|c|c|}
\hline & Counties & Area (square miles) & Population \\
\hline Bay Area & $\begin{array}{l}9 \text { Counties: All of Alameda, Contra } \\
\text { Costa, Marin, Napa, San Francisco, } \\
\text { San Mateo, and Santa Clara counties, } \\
\text { western portion of Solano County, and } \\
\text { southern portion of Sonoma County }\end{array}$ & 5,600 & 7.4 million \\
\hline South Coast & $\begin{array}{l}4 \text { Counties: Los Angeles County except } \\
\text { for portion covered by Antelope Valley } \\
\text { APCD, Orange County, western portion } \\
\text { of San Bernardino County, and western } \\
\text { and central portions of Riverside County }\end{array}$ & 10,743 & 16.8 million \\
\hline San Joaquin Valley & $\begin{array}{c}\text { Counties: All of Fresno, Kings, Madera, } \\
\text { Merced, San Joaquin, Stanislaus, and } \\
\text { Tulare counties and western portion of } \\
\text { Kern County }\end{array}$ & 23,490 & 3.9 million \\
\hline
\end{tabular}

Table 1

Counties, Area and Population Characteristics of the Bay Area, South Coast and San Joaquin Valley [Source: BAAQMD, 2009; SCAQMD, 2010a; \& SJVUAPCD 2009]

The differences seen in threshold approaches can in part be attributed to the regional characteristics of these three districts. Table 2 provides a comparison of the different adopted or proposed thresholds, approaches, implementation and development processes used by the Bay Area, South Coast and San Joaquin Valley. This table was developed from a combination of interviews, air district documents, and from updating and expanding upon a table developed by Jeane Berry at the Sacramento Metropolitan Air Quality Management District. 


\begin{tabular}{|c|c|c|c|c|}
\hline & & Bay Area Air Quality Management District & $\begin{array}{l}\text { South Coast Air Quality Management District } \\
\text { (proposed thresholds for residential, commercial, mixed use \& plans) }\end{array}$ & $\begin{array}{l}\text { San Joaquin Valley Unified Air Pollution } \\
\text { Control District }\end{array}$ \\
\hline \multirow{5}{*}{ 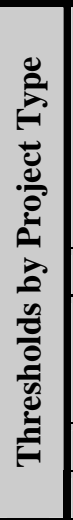 } & $\begin{array}{l}\text { Projects other than Stationary } \\
\text { Sources }\end{array}$ & $\begin{array}{c}\text { Compliance with Qualified GHG Reduction Strategy } \\
\text { OR } \\
\text { 1,100 MT of CO2e/yr } \\
\text { OR } \\
\text { 4.6 MT CO2e/SP/yr (residents + employees) } \\
\text { (emissions from land use sectors including operations and trips) }\end{array}$ & $\begin{array}{c}\text { Residential = 3,500; Commercial = 1,400; Mixed Use = 3,000 } \\
\text { OR } \\
\text { Residential/Commercial/Mixed Use = 3,000 MT of CO2e/yr } \\
\text { OR } \\
\text { 4.8 MT CO2e/SP/yr* (residents + land use employment) (2020 Target) } \\
\text { 3.0 MT CO2e/SP/yr* (residents + land use employment) (2035 Target) }\end{array}$ & Reduction of $29 \%$ from BAU \\
\hline & Stationary Sources & $10,000 \mathrm{MT}$ of CO2e/yr & $10,000 \mathrm{MT}$ of $\mathrm{CO} 2 \mathrm{e} / \mathrm{yr}$ & BPS \\
\hline & Plans & $\begin{array}{l}\text { Compliance with Qualified GHG Reduction Strategy } \\
\text { OR } \\
6.6 \mathrm{MT} \text { CO2e/SP/yr (residents + employees) }\end{array}$ & $\begin{array}{l}\text { 6.6 MT CO2e/SP/yr (residents + employees) (2020 target) } \\
\text { 4.1 MT/year CO2e/SP/yr* (residents + employees) (2035 target) }\end{array}$ & None \\
\hline & Construction & None & $30 \mathrm{yr}$ amortization applied to operational emissions & BPS \\
\hline & Maximum Emission Limit & None & None & None \\
\hline \multirow{4}{*}{ 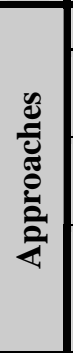 } & Tiered & No, but provides three options for compliance. & Yes, five tiers. & Yes, four tiers. \\
\hline & Qualitative & Consistent with a qualified GHG Reduction Strategy & $\begin{array}{l}\text { Tier 1: Applicable CEQA Exemptions } \\
\text { Tier 2: Consistent with a GHG reduction plan }\end{array}$ & $\begin{array}{l}\text { Tier 1: Applicable CEQA Exemptions } \\
\text { Tier 2: Consistent with a GHG reduction plan }\end{array}$ \\
\hline & Quantitative & Bright Line Threshold based on Gap Analysis Efficiency & $\begin{array}{l}\text { Tier 3: 90\% Capture Rate } \\
\text { Tier 4 (Option 3): Efficiency based threshold }\end{array}$ & None \\
\hline & Performance Standards & None & $\begin{array}{c}\text { Tier } 4 \text { (option 1): Uniform Percent Reduction: 28\% reduction } \\
\text { Tier } 4 \text { (Option 2): Early Implementation of AB } 32 \text { Scoping Plan Measures } \\
\text { Tier 5: Mitigation Offsets }\end{array}$ & $\begin{array}{l}\text { Tier 3: Implements BPS } \\
\text { Tier 4: Project specific GHG quantification } \\
\text { and reduces GHGs by } 29 \%\end{array}$ \\
\hline \multirow{12}{*}{ 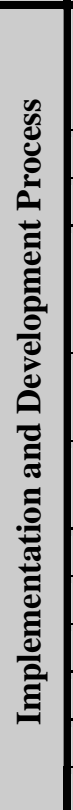 } & $\begin{array}{l}\text { Recommendations for GHG } \\
\text { Reduction Strategies }\end{array}$ & $\begin{array}{l}\text { Consistent with AB } 32 \text { and CEQA Guidelines } \S 15183.5 \text {, includes measures } \\
\text { to reduce emissions and provides a plan to meet } 1990 \mathrm{GHG} \text { levels or } 15 \% \\
\text { below 2008, or meets the plan efficiency threshold }\end{array}$ & $\begin{array}{l}\text { Certified CEQA document; Emissions inventory; GHG emission reduction target as } \\
\text { stringent as AB 32; Monitoring and enforcement }\end{array}$ & $\begin{array}{l}\text { Specify in law or approval by the lead agency } \\
\text { and supported by a CEQA compliant } \\
\text { document }\end{array}$ \\
\hline & Off-site or offsets & Off-site mitigation allowed; Pursuing off-set mitigation fund & Proponent can purchase qualified mitigation credits & Allows off-site mitigation or use of offsets \\
\hline & Models & URBEMIS and BGM & CalEEMod $^{\mathrm{TM}}$ & None \\
\hline & Data & $\begin{array}{c}\text { For Gap Analysis: Used data from past } 7 \text { yrs. of CEQA projects; Statewide } \\
\text { GHG emissions inventory; inventory for all cities/counties } \\
\text { For Stationary Sources: stationary permits from previous } 3 \text { years }\end{array}$ & $\begin{array}{l}\text { For Industrial Threshold: Used data from 1,297 stationary projects } \\
\text { For Land Use Sources: Used data from } 798 \text { land use projects with CEQA documents for } \\
\text { year } 2007 \text { \& } 2008\end{array}$ & $\begin{array}{l}\text { From the AB } 32 \text { Scoping Plan which implies } \\
\text { that a } 29 \% \text { GHG reduction from BAU will get } \\
\text { the State to its goal }\end{array}$ \\
\hline & Public Participation & 4 public hearings; workshops following Board approval & $\begin{array}{l}\text { GHG stakeholder group established; met } 7 \text { times in } 2008,7 \text { times in } 2009 \text { and once in } \\
\text { 2010; all meetings were open to the public }\end{array}$ & Development of BPS is a public process \\
\hline & Costs & $\begin{array}{l}\text { Costs reflect consulting work for Bay Area's CEQA update. EDAW: \$98,000 } \\
\qquad \& 15,000 \text {; Jones \& Stokes: } \$ 25,000 ; \text { Rimpo: } \$ 25,000\end{array}$ & Staff time $>450$ hrs + OPR staff effort & 4 staff people \\
\hline & CEQA Docs Reviewed / Yr. & Approximately 25-50 & Approximately 430 & Approximately 106 \\
\hline & Opposition & Several cities; BIA & BIA and environmentalists have some concerns & Environmentalists \\
\hline & Support & CBD; AG; Triad Development; Breathe CA & CBD and AG (in stakeholder meetings) & Local agencies; permitted sources; BIA \\
\hline & AG Comments & Submitted letters of support and testified at hearings & Supportive of industrial threshold based on feedback at working group meetings & Submitted letter of criticism \\
\hline & Board Action & Adopted 06/02/10 & Adopted stationary threshold on $12 / 5 / 08$; deferred area source thresholds & Adopted 12/17/09 \\
\hline & Next Steps & Continue workshops for cities on threshold/using BGM & Take residential/commercial/mixed use threshold to Board & Develop 2002-2004 baseline for projects \\
\hline
\end{tabular}

Adopted or Proposed GHG Thresholds of Significance by California Air Districts

[AG - California Attorney General

BAU - Business As Usua

CBD - Center for Biological Diversity

BGM - Bay Area Greenhouse Gas Mod

BPS - Best Performance Standards

CalEEMod $^{\mathrm{TM}}$ - California Emissions Estimator Mode

CEQA - California Environmental Quality Act

CO2e - Carbon Dioxide equivalent

MT - metric tons

URBEMIS - Urban Emissions model] 
The above comparison table highlights the key similarities and differences between the proposed and adopted approaches that the Bay Area, South Coast and San Joaquin Valley have used in developing GHG thresholds of significance. However, some of the information listed in the table requires a more detailed explanation. The following provides a more detailed description of the proposed or adopted thresholds and the methods taken to develop them. It also describes the key criticisms or praises received by the air districts by the Attorney General’s Office or other commenting groups.

\section{Bay Areas Air Quality Management District (Bay Area)}

The Bay Area has adopted GHG thresholds for land use projects, plans and stationary sources. For land use projects, the Bay Area developed two quantitative thresholds and one qualitative threshold to provide lead agencies with options for compliance with CEQA. The two quantitative thresholds are a 1,100 MT CO2e/yr numerical or "bright-line" threshold and an efficiency threshold of 4.6 MT CO2e/SP/yr for projects and 6.6 MT CO2e/SP/yr for plans. The 1,100 MT CO2e/yr bright-line threshold is the level that new land use projects must meet in order for the Bay Area to achieve the AB 32 goal of reaching 1990 emission levels by 2020. This threshold was derived from an eight step "gap-based" analysis that calculated the difference between projected 2020 emissions with the AB 32 Scoping Plan measure reductions and the reductions needed to reach 1990 levels. A sensitivity analysis was then used to derive the numerical threshold associated with the gap based on mitigation effectiveness. To aid lead agencies in evaluating a project's compliance with this threshold, the Bay Area developed screening levels for typical project types that would not exceed the 1,100 MT CO2e/yr threshold. Using these tables, the 1,100 MT CO2e/yr threshold would typically apply to projects larger than 56 single-family residential units, or a $19,000 \mathrm{ft}^{2}$ commercial strip mall, or an $8,000 \mathrm{ft}^{2}$ supermarket. This approach was supported by the AG for providing a clearly defined and appropriately stringent threshold. Criticism of this threshold contends that the threshold is short sided because it does not look beyond 2020.

The Bay Area also developed an efficiency threshold of 4.6 MT carbon dioxide equivalent per service population per year (CO2e/SP/yr) noting that projects that are highly efficient, such as mixed-use projects, 
may not be able to meet the bright-line numerical threshold. This threshold is derived from dividing the statewide emissions land use sector goal by the 2020 service population (i.e. population and employment) projections. This threshold promotes mixed use, infill and transit oriented development (TOD) projects by allowing highly efficient projects to comply with GHG emission requirements under CEQA. While this caveat allows efficient projects to meet a threshold, the AG cautions the use of an efficiency threshold in situations where a project's emissions are very large, as the project could still be considered significant under CEQA's fair argument provision (Interview, 2010). According to one interviewee, the danger in using the efficiency threshold for projects that have very high emissions is that lead agencies could quickly "use up the community budget” of allowable emissions with only a few large projects. For this reason, some critiques suggest that a maximum emissions limit be adopted along with efficiency thresholds to deter the use of efficiency thresholds for projects that are not highly-efficient. Others contend that the efficiency thresholds are too stringent and creates disincentives to infill, TOD and mixed-use projects (CBIA v. BAAQMD, 2010). While there are some concerns for appropriate use of efficiency thresholds, when applied as intended they can reduce barriers for transit-oriented development, infill and mixed-use projects.

The Bay Area used a similar approach for developing a GHG threshold to apply to general plans in the region. The efficiency threshold of 6.6 MT CO2e/SP/yr for general plans uses the same calculation as the efficiency threshold for land use projects, except that the total statewide emissions goal is used instead of just the land use sector emissions goal. These thresholds will be reevaluated as updated statewide projections for numerical GHG emission goals, population and employment become available. If a general plan meets the 6.6 MT CO2e/SP/yr threshold, the plan will generally be considered not significant under CEQA. This threshold is not intended for use by plans other than general plans, such as specific plans. Plans other than general plans should apply the project efficiency threshold of 4.6 MT CO2e/SP/yr. Since the efficiency thresholds for projects and plans are based solely on statewide data, these thresholds can theoretically be adopted by other lead agencies throughout the State. However, the stringency of this threshold makes it difficult to apply it broadly to projects other than highly-efficient projects. For example, under this threshold, a small rural development project would most likely be determined significant, 
triggering an EIR. For this reason, the Bay Area provides other more appropriate threshold options to use for projects that are not highly efficient.

In addition to the two quantitative thresholds, the Bay Area has also adopted a qualitative threshold that specifies that land use projects that are consistent with a qualified GHG reduction strategy are considered less than significant. This approach encourages cities and counties to address climate change at the programmatic level through general plans and GHG reduction strategies. Unique from the other districts, the Bay Area establishes criteria for what qualifies as a GHG reduction strategy. Other air districts may not follow suit now that the CEQA Guidelines specify what a GHG reduction strategy should include. Generally, if a plan meets the requirements in the State CEQA Guidelines $\S 15183.5$ (b), it can allow for CEQA streamlining of projects that are consistent with the plan. However, until such plans are in place, project proponents will likely use one of the quantitative thresholds for compliance with CEQA. The California Air Resources Board (CARB), Attorney General (AG) and California Air Pollution Control Officers Association (CAPCOA), OPR and CNRA all promote the use of programmatic approaches, such as SCSs, to reduce future GHG emissions from projects.

Figure 1 below is a flow chart developed by the environmental consulting firm, Ascent Environmental, Inc., to help lead agencies apply the GHG threshold options for evaluating GHG emissions of projects or plans in the Bay Area. This diagram provides a visual representation of the guidance the Bay Area has developed for lead agencies. 


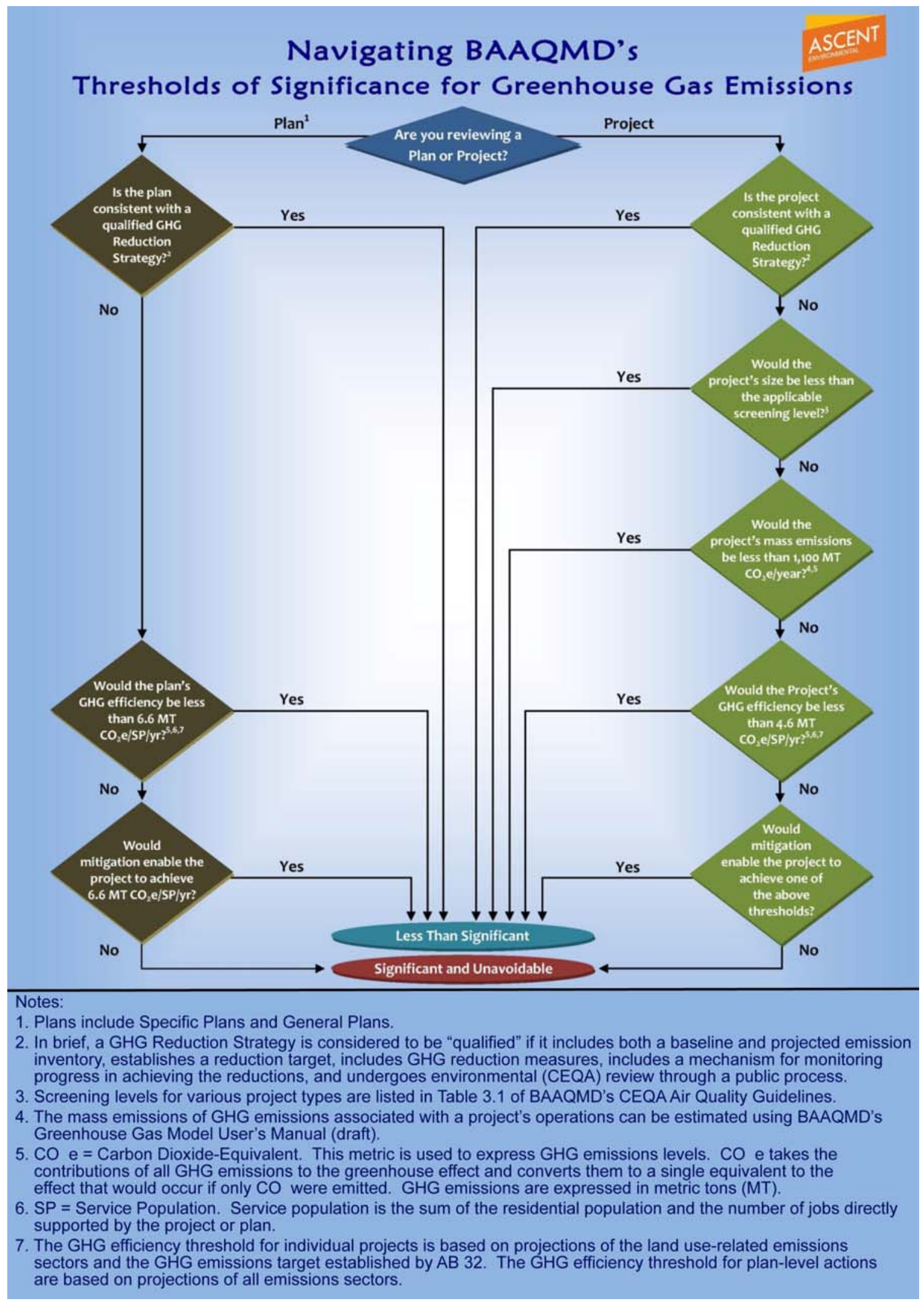

\section{Figure 1}

Navigating BAAQMD's Threshold of Significance for GHG Emissions

[Recreated from Ascent Environmental, Inc., Sacramento, CA (www.ascentenvinc.com), 2010] 
The bright-line industrial stationary source threshold of 10,000 MT CO2e/yr was developed using a market capture approach. As described in the CAPCOA white paper, the rational behind this approach is to exclude smaller projects "from potentially burdensome requirements to quantify and mitigate GHG emissions under CEQA,” while capturing the majority of emissions (CAPCOA, 2008, p.44). Bay Area developed their threshold by estimating the amount of $\mathrm{CO} 2$ emissions produced from combustion sources for all permitted stationary sources in 2005, 2006 and 2007 and then determining what numerical threshold corresponded to capturing 95\% of those emissions. The Bay Area found that while stationary sources with emissions that exceed the 10,000 MT threshold account for less than $10 \%$ of permitted stationary sources, they make up approximately 95\% of all GHG emissions. In other words, with a 10,000 MT threshold, the $90 \%$ of permitted stationary sources that represent the remaining $5 \%$ of GHG emissions will not be subject to further environmental review for GHG emissions. The Bay Area considers this threshold an interim policy that will be reevaluated once a statewide cap-and-trade program is implemented.

\section{South Coast Air Quality Management District (South Coast)}

The South Coast has adopted a threshold for stationary sources and proposed GHG thresholds for land use projects and plans. In 2008, the South Coast adopted a 10,000 MT CO2e/yr threshold for stationary sources. While this threshold is identical to the threshold later developed by the Bay Area, the South Coast’s market capture approach used a 90\% GHG emission capture rate, while the Bay Area used a 95\% capture rate. To develop their industrial threshold, the South Coast looked at 1,297 permitted natural gas facilities from 2006-2007 and found that the number of facilities associated with $90 \%$ of all natural gas usage, corresponded to approximately 10,000 MT CO2/yr. For the South Coast air basin, only about 10\% of permitted stationary sources will have emissions greater than the 10,000 MT CO2/yr threshold, which represents $90 \%$ of all GHG emissions from permitted stationary sources. Similar to the Bay Area threshold, this threshold captures most emissions, "while setting the emission threshold high enough to exclude small development projects that will contribute a relatively small fraction of the cumulative statewide GHG emissions" (CAPCOA, 2008, p. 43). While this threshold is generally supported, some experts that were 
interviewed criticize the emission capture rate approach claiming that choosing the level of emissions to capture is subjective.

The district is currently developing a 5 tiered approach for the thresholds for land use projects and plans. The tiered approach consists of qualitative, quantitative and performance standards to provide greater flexibility (see Figure 2). Consistent with the CARB's guidance, a project is considered not to be significant in the first two tiers if CEQA exemptions apply or a project is consistent with a GHG reduction strategy. In the third tier, a project is considered significant if its emissions exceed the screening levels of 3,000 MT/yr CO2e for all land use types. The South Coast also provides an option for lead agencies to use a residential threshold of 3,500 MT/yr CO2e, a commercial threshold of 1,400 MT/yr CO2e, and a mixed use threshold of 3,000 MT/yr CO2e, if applied consistently for all projects. The bright-line thresholds in this tier are based on a review of 711 CEQA projects from years 2007-2008 using a 90\% emissions capture rate approach. The fourth tier provides three options for compliance: 1) percent emission reduction from BAU, 2) early implementation of applicable AB 32 Scoping Plan measures, and 3) efficiency targets for 2020 or 2035 of 4.8 MT CO2e/SP/yr for projects or 6.6 MT CO2e/SP/yr for plans and 3.0 MT CO2e/SP/yr for projects or $4.1 \mathrm{MT} \mathrm{CO2e/SP/yr} \mathrm{for} \mathrm{plans,} \mathrm{respectively.} \mathrm{If} \mathrm{a} \mathrm{project} \mathrm{meets} \mathrm{any} \mathrm{of} \mathrm{the} \mathrm{options} \mathrm{in} \mathrm{tier} \mathrm{4,} \mathrm{a}$ project will be considered not significant. While South Coast does not give a recommendation for option 1, South Coast staff plans to reference the San Joaquin Valley and discuss the challenges of this approach to lead agencies (SCAQMD, 2010b). Option 2 is incorporated in option 2 (SCAWMD, 2010). The efficiency target in this tier follows the methodology presented in the CAPCOA paper and used by the Bay Area. However, the discrepancy in the project level efficiency thresholds developed by the Bay Area and South Coast is due to the fact that the South Coast used the statewide 2020 employment values for all land use sectors, instead of the total 2020 statewide employment values for all sectors as the Bay Area used (SCAQMDb, 2010). The fifth tier obligates a project proponent to provide mitigation offsets for the 30year life of the project. This proposal is still in the development stages and may change significantly prior to its adoption. Like the stationary threshold, these thresholds are also generally supported, although some believe that methodology is arbitrary. 


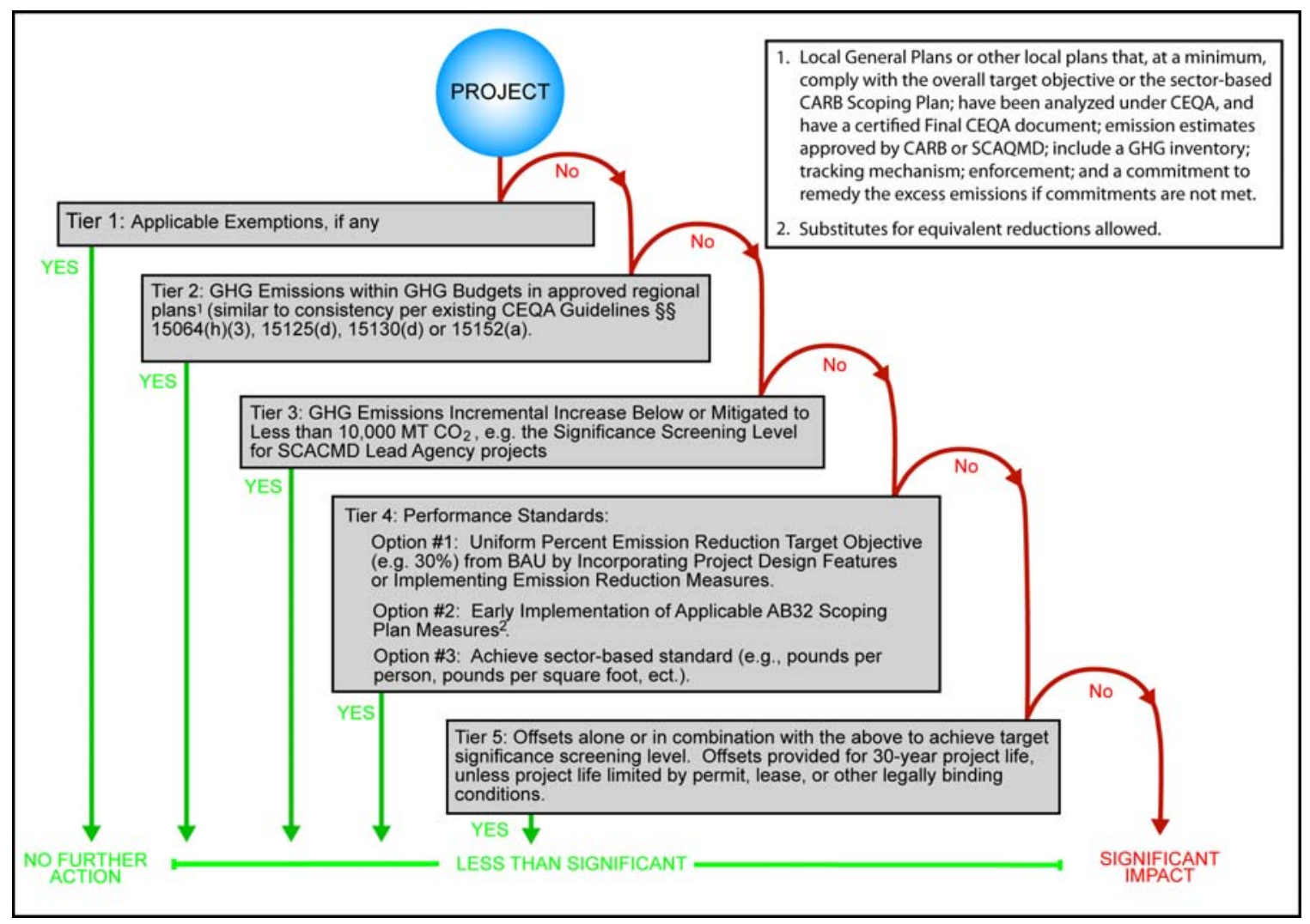

\section{Figure 2}

\section{Draft South Coast Air Quality Management District Tiered Decision Tree Approach}

[Source: Recreated from SCAQMD, 2008]

\section{San Joaquin Valley Unified Air Pollution Control District (San Joaquin Valley)}

On December 17, 2009, the San Joaquin Valley adopted guidance for addressing GHG emissions under CEQA for land use projects and stationary sources. Similar to the Bay Area, the San Joaquin Valley relies on the goals in AB 32 to establish its guidance. However, unlike the Bay Area, the San Joaquin Valley concludes that it is not feasible to establish a numerical threshold based on available science. Instead, the San Joaquin Valley approach relies on the use of performance standards.

Under this approach, if a project does not already comply with a GHG reduction strategy or is otherwise exempt, it can still be considered less than significant if the project incorporates district approved best performance standards (BPS) that are designed to reduce the emissions associated with a project by $29 \%$ 
from BAU. Best Performance Standards are the most effective, achievable in practice standards that are economically feasible. This approach is based on CARB's finding that statewide emissions must be reduced by 29\% from BAU to achieve 1990 emissions by 2020. The San Joaquin Valley defines BAU as the projected 2020 emissions from a 2002-2004 baseline without GHG reduction measures (SJVUAPCD, 2009). Under this approach, projects that have emissions that are $29 \%$ less than they would have been under the regulatory controls during the 2002-2004 base year, would be considered less than significant. Project applicants that do not implement BPS, must quantify project emissions and otherwise show that they have reduced their emissions by 29\% under a 2002-2004 baseline for a project to be considered less than significant (SJVUAPCD, 2009).

To provide consistency for how BPS GHG reductions are applied to projects, the San Joaquin Valley is developing a list of BPS for stationary sources and GHG emissions reduction measures for land use projects. While these are being developed, the San Joaquin Valley provides a GHG emissions reduction calculator and a link to the CAPCOA Quantifying GHG Measures Report as interim guidance on their website for use until GHG emission reduction measures are adopted by the district. In addition, the San Joaquin Valley is developing specific values for GHG emission baseline levels for different categories of project types.

While this approach may have been the only politically feasible approach that the San Joaquin Valley could adopt, the AG warned that it "will not withstand legal scrutiny and may result in significant lost opportunities for the Air District and local governments to require mitigation of greenhouse gas (GHG) emissions” (Brown \& Sullivan, 2009, p. 1). Specifically, these thresholds were criticized because the methodology has numerous flaws. First, the methodology does not include a calculation for the amount of GHG emission reductions needed to achieve the AB 32 target. In addition, the methodology follows a logical fallacy that if future projects reduce emissions by 29\% from BAU, then the statewide 2020 target of reducing BAU emissions by $29 \%$ would also be achieved. However, there is no evidence presented to support this claim. Additionally, since project proponents are being told to compare the real emissions from their project to a hypothetical project built under 2004 air quality regulations, this threshold creates a 
situation that allows for double-counting of emission reductions that are already (or will be) required by regulation and could allow one to "game" the system by inflating the amount of emissions actually reduced (Brown \& Sullivan, 2009, p. 3). For example, if project proponents use this threshold, they will be taking credit for GHG reductions already required by law such as routine updates to Building Energy Efficiency Standards (Title 24) and the Green Building Standards Code requirements effective in January 2011. Furthermore, this approach potentially allows for all projects, no matter how large their emissions, to avoid undergoing environmental review because even a project with very large emissions after reducing emissions by $29 \%$ from BAU would be considered less than significant under this threshold (Brown \& Sullivan, 2009). Overall, this threshold allows for project proponents to "reverse engineer a less-thansignificant finding through post-hoc calculations and imbedded assumptions” (Crockett, Collins-Burgard, \& Vespa, 2010, p. 15)

While the AG has outlined a number of criticisms and questions the legal defensibility of this approach, another expert interviewed suggested that there "is some value in the approach it that it is relatively efficient.” According to this interviewee, if another air district were able to document with substantial evidence what BAU is, and could also document with substantial evidence how getting a certain percentage below that would lead to a less than significant impact, then the approach could have some merit. However, without substantial evidence to support the threshold, the approach will likely not be defendable.

\section{Common Themes from Survey of Air Districts Without Adopted Thresholds}

Based on the survey responses from air districts that do not have adopted thresholds, the challenges and progress experienced by the Bay Area, South Coast and San Joaquin Valley has influenced the way these districts are proceeding with developing and adopting guidance of their own. The level of response from air districts that returned completed surveys represents about $1 / 3$ of all air districts that do not have adopted GHG thresholds. However, the air districts that were solicited are ones that are thought to typically review projects under CEQA. Thus, the viewpoints from the 9 air districts that replied to the survey can be considered representative of the majority of air districts that review projects under CEQA that do not yet 
have adopted thresholds. The responses from the open-ended survey questionnaire were organized into different categories of responses. The common themes that emerged from this analysis were that air districts are leading regional and inter-agency coordination efforts to develop GHG thresholds, considering similar approaches, facing similar challenges in developing guidance and would like greater assistance from the State.

\section{Regional and Inter-Agency Coordination}

One of the common themes that emerged in the survey responses was that most districts are participating in regional or inter-agency discussions to develop thresholds. Several air districts are working together to develop a regional GHG threshold. For example, since December the Sacramento Metropolitan Air Quality Management District has convened a stakeholder committee comprised of other air districts in the region including Feather River AQMD, Yolo/Solano AQMD, County of El Dorado AQMD and Placer County APCD to evaluate approaches for developing thresholds and to hopefully develop a regional threshold that each district will adopt. The stakeholder group has had representatives from each of the three districts that have adopted thresholds give presentations on their approaches and has had other consultants present on the pros and cons of each approach. Even though not all air districts in the region typically review projects for their adequacy under CEQA, one interviewee commented that all of the districts are participating in this effort because "GHGs has made it so that even those that [do not employ the measures set forth by] CEQA are now engaged.” This trend could be explained through a combination of reasons including the interest the Attorney General's Office has taken on this topic and need for a multi-faceted approach to reduce GHG emissions that contribute to climate change. Furthermore, with different GHG thresholds of significance already being adopted by cities and counties in the region, the air districts are interested in providing a more consistent approach.

Other districts have also shown leadership to develop regional thresholds. In particular, the San Luis Obispo County APCD (San Luis Obispo) and San Diego County APCD (San Diego) have undertaken separate efforts in their regions to develop thresholds that can be consistently applied throughout the region. Since 2008, the San Luis Obispo has facilitated a GHG stakeholder group comprised of all the cities 
in the region and the county to collaborate on climate change planning efforts including the development of GHG emission inventories, climate action plans and GHG thresholds of significance. This coordinated effort has resulted in the completion of GHG emission inventories for each city and the county, and plans for the development of climate action plans for each city and the county. It is the expectation that a threshold developed by the San Luis Obispo and vetted through this stakeholder group will result in a threshold that each local jurisdiction will adopt to use in determining the significance of GHG emissions.

Similarly, the San Diego has played "an advisory and convening role in coordinating CEQA GHG approaches among the 19 jurisdictions in the San Diego region,” according to a survey respondent. While the San Diego does not have any plans to adopt guidance, the County of San Diego and City of San Diego have adopted interim GHG thresholds of significance, both of which incorporate a screening threshold of 900 MT CO2e and then requiring a reduction on 30\% if this threshold is exceeded based on CAPCOA's quantitative market capture threshold. However, the County is watching what air districts around the State are doing to see what approaches are most legally defensible before deciding how to precede. While all jurisdictions agree that a consistent regional approach is preferred, political challenges exist that may make it difficult to agree on common thresholds.

\section{Approaches Considered}

All of the air districts that were surveyed indicated that they plan to adopt GHG thresholds of significance in the future, except for one. Of these air districts, all stated that they are tracking the progress of the South Coast, Bay Area and San Joaquin Valley. Most of these districts are gathering information on the approaches and individually evaluating the strengths and weaknesses of each approach. Only a few are far enough along in the process where they have selected an approach that they intend to pursue. All of these air districts indicate that they are following the methodologies of the Bay Area and/or South Coast adopted or proposed approaches. While some air districts are in the process of collecting the data needed to develop regionally-based thresholds of significance, others intend to take thresholds from other districts and develop justification to support their choice. However, since any threshold adopted by a lead agency must 
be supported by substantial evidence, other agencies should be cautious about adopting the bright line thresholds adopted by the Bay Area and South Coast that are derived from area-specific data.

\section{Key Challenges Air Districts Confront in Developing Guidance}

In selecting approaches for developing GHG thresholds of significance, air districts face common challenges. Of the air districts that stated that they plan to adopt thresholds, the main concern they have is the legal defensibility of thresholds that they propose. However, according to one legal expert interviewed, it is probably not appropriate to challenge air districts for the thresholds they adopt because unless the thresholds are being used by the air district as a lead agency, the adopted thresholds are simply guidance that other lead agencies can adopt and use at their discretion. Nevertheless, the top concern of air districts is that the guidance they put forth is legally defendable by lead agencies that opt to adopt it and use it.

Another related challenge that some air districts mentioned is the economic and political feasibility of developing guidance. Not only are air districts concerned about the possible economic burden placed on project applicants based on guidance they adopt, but they are also concerned about the cost of developing the guidance itself, overseeing its implementation and managing the increased workload of reviewing projects that historically were not subject to CEQA review. As seen in Table 2, developing the substantial evidence needed to produce a legally defendable threshold can be time consuming and expensive. Likewise, not having the support of the air district board could halt any progress to develop guidance.

\section{Assistance Needed}

Air districts facing the challenges of threshold development identified assistance that would be helpful to them in developing GHG guidance. The number one request from air districts is for the State to adopt a recommended threshold of significance or a detailed methodology to develop GHG thresholds. Specifically, one air district requests that the State develop a threshold dependent on project size. The primary concern that air districts have with establishing their own regional thresholds is the lack of statewide consistency. A secondary concern that was expressed by survey respondents is that many air districts feel that they lack resources (ie. time, money, staff, training, etc.) needed to develop sound 
guidance. It would take much fewer resources and would "alleviate the pressure" and "reduce the political hurdles" on individual air districts and lead agencies to develop thresholds if "CARB would continue their efforts to develop a statewide threshold,” according to survey respondents. Furthermore, having statewide consistency would reduce the "regulatory uncertainty" that is causing "negative impacts... on the recovery of California’s struggling economy” (Crockett, Collins-Burgard, \& Vespa, 2010, p. 16). However, a statewide threshold may not be able to accurately reflect the differences in geography, politics and economic characteristics of the diverse cities and counties throughout the State of California.

As described above, the development of GHG thresholds of significance across the State is an emerging practice that will continue to evolve through political and legal discourse. While three air districts have adopted or proposed GHG thresholds of significance and at least 8 other districts plan follow a similar course, a standard methodology for developing GHG thresholds that can be followed statewide has yet to materialize. Although some cities and counties have adopted GHG thresholds of significance, air districts are beginning to fill this void with regionally applicable guidance. 


\section{DISCUSSION}

Although the state of the practice for developing GHG thresholds of significance is evolving, the commonalities between the proposed or adopted thresholds and viewpoints of other districts point to some emerging trends. Some of these trends include providing flexibility, encouraging a programmatic approach and adopting bright-line thresholds as options. Through developing these approaches, the Bay Area, South Coast and San Joaquin Valley have contributed valuable lessons for other districts. However, these insights offer limited benefit for other districts because some of the approaches may not be easily transferable. Thus, more specific assistance and research could be useful as air districts continue to develop guidance.

\section{Emerging Trends}

While the Bay Area, South Coast and San Joaquin Valley have all developed unique guidance, there are several similarities between the thresholds developed. For example, all of the approaches provide flexibility for projects in meeting the adopted requirements. The South Coast and San Joaquin Valley approaches afford flexibly through the tiered decision tree framework, while the Bay Area gives options for meeting requirements. Another commonality is that all three districts include a preference for a programmatic approach. While the City of San Carlos is the only jurisdiction that currently has a qualified CAP in place that allows for a streamlined review of GHG emissions under CEQA, all three air districts encourage this approach to become the leading method for addressing GHG emissions under the CEQA framework. A third notable trend is that districts are developing bright-line GHG thresholds for the sake of clarity and ease of implementation, despite previous claims that establishing a numerical threshold for GHG emissions was too speculative. The Bay Area and South Coast both adopted a bright-line threshold of 10,000 MT CO2e/yr for stationary sources and have adopted or proposed bright-line thresholds for land use projects. Furthermore, both have developed efficiency-based thresholds to provide flexibility for highly efficient projects and plans. Together, these emerging trends provide a good starting point for other districts to develop their own standards of guidance. 


\section{Transferability}

The Bay Area, South Coast and San Joaquin Valley have paved the way for other districts to develop GHG thresholds by testing the political feasibility and legal defensibility of various approaches, developing detailed methodologies for these approaches and providing valuable lessons learned. While there have not been any court cases that have challenged the use of these thresholds, comments letters from the Office of the Attorney General have given insight into the defensibility of the Bay Area and San Joaquin Valley approaches. While the AG supports the Bay Area approach, it does not endorse the San Joaquin Valley approach because it "will not withstand legal scrutiny and may result in significant lost opportunities for the Air District and local governments to require mitigation of greenhouse gas (GHG) emissions” (Brown \& Sullivan, 2009, p. 1). Although there are differing legal opinions on the defensibility of any of the thresholds, air districts should be wary of promoting the approach adopted by the San Joaquin Valley in preference of approaches adopted by the Bay Area.

While the Bay Area and South Coast have laid the groundwork for other air districts to adopt thresholds based on their methodologies, their methods may not be easily transferable to every region. Although any air district can develop their own bright-line threshold by following the eight step "gap-based approach" in Appendix D of the Bay Area CEQA Air Quality Guidelines, some air districts might find this methodology hard to apply to their region because of the high cost and data requirements. Not only would some air districts lack data such as a robust GHG emissions inventory or detailed historical information on project types, but some air districts might also lack an adequate sample size of projects needed for this methodology. Furthermore, while the gap analysis methodology to develop a bright line threshold should be easily transferable to areas with similar characteristics to the Bay Area such as higher densities, transit access and a large range of GHG emissions, this approach could produce unfeasible thresholds for regions that do not have those characteristics. Following this same methodology, less populated and lower density areas could end up with more stringent thresholds than the Bay Area that would be politically unfeasible to adopt and that would likely result in more statements of overriding considerations instead of more GHG reductions. In these cases, the methodology might need to be adapted to account for regional differences in geography, politics and economic characteristics to produce a feasible threshold. 
Likewise, while the South Coast's capture rate approach seems easy to follow, without a wide range of project sizes and types, an emission capture rate could require a large number of projects to analyze and mitigate their emissions, which is contrary to the intent of this approach. Furthermore, the resource requirements of these data-intensive methods could make it difficult for some smaller air districts to replicate these approaches. While it might seem appealing for air districts to simply use a numerical bright line threshold that has been adopted in another region, air districts should be cautious in using other air district's thresholds because they might not be able to rely on the substantial evidence that supports the thresholds because the thresholds were developed based on regionally-specific data.

While the bright-line thresholds are based on area-specific data, the efficiency thresholds produced by the Bay Area and South Coast are based on statewide data and can therefore theoretically apply to anywhere in the State. However, they are designed as stringent thresholds to use for highly efficient projects such as infill, mixed use and TOD. Projects of these types in regions with lower densities and minimal access to transit might not be able to achieve these thresholds because density, followed by VMT, is the greatest factor in meeting these thresholds.

\section{Research Needed}

Although a substantial amount of helpful guidance and work has been developed that air districts can use in developing GHG thresholds, more assistance and research is needed. While the identified emerging trends

provide useful methodologies and thresholds for comparable air districts to follow, detailed guidance is still needed for areas with fewer resources and overall emissions. Future methods should consider the unique characteristics of smaller regions such as higher agricultural uses and smaller project sizes. Concurrently, the State should provide more incentives for local and regional governments to develop programmatic approaches that provide for GHG streamlining under CEQA. Furthermore, more academic research on this topic is needed. In particular, a review of CEQA documents to see if and how guidance from the Bay Area, South Coast and San Joaquin Valley is being followed would further explain the state of the practice. OPR has begun a list of CEQA documents that mention GHG emissions, but this list does not describe how the 
documents address GHG emissions nor if a threshold was used to aid in the determination of significance. While this research aims to explain the state of the practice for how air districts are developing GHG thresholds of significance, a review of CEQA documents could help determine the overall effectiveness of using CEQA as a tool to reduce future GHG emissions. 


\section{REFERENCES}

Ascent Environmental, Inc. (2010). Navigating the Bay Area Air Quality Management District’s Thresholds for Greenhouse Gas Emissions. Sacramento, CA. Retrieved December 1, 2010 from http://ascentenvinc.com/wordpress/wp-content/uploads/2010/12/Navigating-BAAQMDFlowchart.pdf

Baird, B. (2009, January 9). Comments re GHG Significance Thresholds under CEQA. [Web log comment] Retrieved May 25, 2010 from http://www.arb.ca.gov/lispub/comm2/bccomdisp.php?listname=ceqa-indws\&comment_num $=8 \&$ virt_num $=7$

Bay Area Air Quality Management District. (2010, June). California Environmental Quality Act Air Quality Guidelines. Retrieved July 1, 2010 from http://www.baaqmd.gov/ /media/Files/Planning\%20and\%20Research/CEQA/BAAQMD\%20CE QA\%20Guidelines_June\%202010.ashx

Biological Diversity v. National Highway Traffic Safety Administration. (2008). 538 F.3d 1172, 1215-1217 9th Cir.

Brown, E. \& Richards, J. ( 2009, December 2). California Environmental Quality Act (CEQA) Air Quality Guidelines, Final Draft (dated November 2009); Proposed Thresholds of Significance (dated November 2, 2009). Retrieved March 9, 2010 from http://ag.ca.gov/globalwarming/ceqa/comments.php

Brown, E. \& Sullivan, T. (2009, November 4). Final Draft Staff Report on Greenhouse Gas Emissions Under CEQA. [Comment Letter to the San Joaquin Valley Unified Air District]. Retrieved March 9, 2010 from http://ag.ca.gov/globalwarming/ceqa/comments.php

California Air Pollution Control Officers Association. (2008, January). CEQA \& Climate Change Evaluating and Addressing Greenhouse Gas Emissions from Projects Subject to the California Environmental Quality Act. Retrieved March 27, 2010 from http://www.capcoa.org/download/CAPCOA+White+Paper

California Air Resources Board. (2008a). Preliminary Draft Staff Proposal Recommended Approaches for Setting Interim Significance Thresholds for Greenhouse Gases under the California Environmental Quality Act. Retrieved March 4, 2010 from http://www.arb.ca.gov/cc/localgov/ceqa/meetings/102708/prelimdraftproposal102408.pdf

California Air Resources Board. (2008b). Climate Change Scoping Plan: A framework for change. Retrieved from http://www.arb.ca.gov/cc/scopingplan/document/scopingplandocument.htm

California Building Industry Association v. Bay Area Air Quality Management District. [Petition for Writ of Mandate]. (2010, November 29).

California Environmental Quality Act Guidelines. § 15064.7 (2009, December 30). Retrieved January 15, 2010 from http://ceres.ca.gov/ceqa/docs/Adopted_and_Transmitted_Text_of_SB97_CEQA_Guidelines_Ame ndments.pdf

California Governor's Office of Planning and Research. (2008, June 19). Technical Advisory: CEQA and Climate Change: Addressing Climate Change through California

California Health and Safety Code. Div. 25.5, § 38500; 38501. (2006). Retrieved September 21, 2010 from http://www.leginfo.ca.gov/cgi-bin/calawquery?codesection=hsc\&codebody=\&hits=20 
California Natural Resources Agency. (2009, December). Final Statement of Reasons for Regulatory Action: Amendments to the State CEQA Guidelines Addressing Analysis and Mitigation of Greenhouse Gas Emissions Pursuant to SB97. Sacramento, CA: State Clearinghouse. Retrieved April 24, 2010 from http://ceres.ca.gov/ceqa/docs/Final_Statement_of_Reasons.pdf

California Office of the Attorney General. (2010). California Environmental Quality Act. Retrieved from http://ag.ca.gov/globalwarming/ceqa.php

California Public Resources Code. Div. 13, § 21159.28. (a). Retrieved July 8, 2010 from http://www.leginfo.ca.gov/cgibin/waisgate?WAISdocID=09714111321+0+0+0\&WAISaction=retrieve.

California v. County of San Bernardino. San Bernardino Co. Sup. Ct. Case No. CIVBS 0700329 (2007, August 28).

Center for Biological Diversity v. City of Desert Hot Springs. Riverside Co. Sup. Ct. Case No. RIC464585. (2008, October 6).

Center for Biological Diversity v. Town of Yucca Valley. San Bernardino Co. Sup. Ct. Case No. CIVBS 800607 and 810232. (2009, May 14).

City of Stockton - California Attorney General and the Sierra Club. (2008, September 9). Memorandum of Agreement. Retrieved June 12, 2010 from http://ag.ca.gov/cms_attachments/press/pdfs/n1608_stockton_agreement.pdf

Climate Action Reserve. (2010, August 24). Five states top the list in reducing greenhouse gas emissions: First place claimed by Arkansas, followed by California, New York, Texas and Alabama. Retrieved October 3, 2010 from http://www.climateactionreserve.org/2010/08/24/five-states-topthe-list-in-reducing-greenhouse-gas-emissions/

Cole, P. (1994). Finding A Path Through The Research Maze. The Qualitative Report, Volume 2, Number 1, Spring, 1994. Retrieved September 22, 2010 from http://docs.google.com/viewer?a=v\&q=cache:T70cfSvGfsQJ:shss.nova.edu/faculty/pcole/theQuali tativeReport.pdf+central+tendencies+range+matrix\&hl=en\&gl=us\&pid=bl\&srcid=ADGEESimsL kI12fLdlbaLgy4d0ANXuj4PKs2EjSpMYDu93jEYC01JNUKhSnYqofSHVEIbBaUntVs1E96V2l qf9OThvCeq8LJ49hJI1Hy7jCLEYBPNhNbOfsRvEHVMQ1Lrvxu4eIDP1cE\&sig=AHIEtbTluhF 3V7pXIPjmkP2MwJPud0mUoA

Communities for a Better Environment v. City of Richmond. 184 Cal.App.4th 70. (2010).

Crockett, A., Collins-Burgard, B, \& Vespa, M. (Spring 2010). Another Hot Year: Analyzing Greenhouse Gas Impacts under CEQA. Environmental Law News. 19(1), 7-20.

Environmental Council of Sacramento v. California Department of Transportation. Sacramento Co. Sup. Ct. Case No. 07CS00967 (2008, July 15).

Exec. Order No. 13432, 72 Fed. Reg. 27717 (2007).

Exec. Order No. S-3-05. (2005, June 1). Sacramento: State of California. Retrieved from http://www.dot.ca.gov/hq/energy/ExecOrderS-3-05.htm

Intergovernmental Panel on Climate Change. (2007). Climate Change 2007: Synthesis Report. http://www.ipcc.ch/publications_and_data/ar4/syr/en/spms1.html

Massachusetts v. Environmental Protection Agency, 549 U.S. 497 (2007). 
Miles, M., \& Huberman, A. (1994). Qualitative Data Analysis. Thousand Oaks, CA: Sage.

Morrow, D. (2008, December 5). Errata. [Web log comment] Retrieved June 3, 2010 from http://www.arb.ca.gov/lispub/comm2/bccomdisp.php?listname=ceqa-indws\&comment_num=7\&virt_num=6

MSNBC. (2006, September 27). Schwarzenegger takes center stage on warming:Emissions law 'will change the course of history,' he says at signing event. MSNBC. Retrieved February 8, 2010 from http://www.msnbc.msn.com/id/15029070/

Protect the Historic Amador Waterways v. Amador Water Agency (2004) 116 Cal.App.4th 1099, 1108.

San Joaquin Valley Unified Air Pollution Control District. (2009, December 17). Final Staff Report Climate Change Action Plan: Addressing GHG Emissions Impacts under CEQA. Retrieved February 9, 2010 from http://www.valleyair.org/Programs/CCAP/12-17-09/2\%20CCAP\%20\%20FINAL\%20District\%20Policy\%20CEQA\%20GHG\%20-\%20Dec\%2017\%202009.pdf

San Joaquin Valley Unified Air Pollution Control District. (2010, June 30). San Joaquin Valley Air Pollution Control District Air Monitoring Network Plan. Retrieved June 7, 2010 from http://www.valleyair.org/aqinfo/Docs/02\%20FINAL\%202010\%20monitoring\%20network\%20pla n.pdf

South Coast Air Quality Management District. (2008, October). Draft Guidance Document - Interim CEQA Greenhouse Gas (GHG) Significance Threshold. Retrieved March 26, 2010 from http://www.aqmd.gov/hb/2008/December/081231a.htm

South Coast Air Quality Management District. (2010a, August). About South Coast AQMD. Retrieved December 7, 2010 from http://www.aqmd.gov/aqmd/index.html

South Coast Air Quality Management District. (2010b, September). Minutes for the GHG CEQA Significance Threshold Stakeholder Working Group \#15. Retrieved December 2, 2010 from http://www.aqmd.gov/ceqa/handbook/GHG/GHG.html

United Nations Framework Convention on Climate Change. (2007). Fact sheet: The Kyoto Protocol. Retrieved from http://unfccc.int/2860.php

United States Environmental Protection Agency. (2009). Endangerment and Cause or Contribute Findings for Greenhouse Gases Under Section 202(a) of the Clean Air Act. 40 CFR Chapter I [EPA-HQOAR-2009-0171; FRL-9091-8] RIN 2060-ZA14. Federal Register. Vol. 74, No. 239. Retrieved from http://www.epa.gov/climatechange/endangerment.html

United States Environmental Protection Agency. (2010a). Climate Change: Basic Information. Retrieved October 1, 2010 from http://www.epa.gov/climatechange/basicinfo.html

United States Environmental Protection Agency. (2010b). Fact Sheet: Mandatory Reporting of Greenhouse Gases (40 CFR part 98). Retrieved from

http://www.epa.gov/climatechange/emissions/ghgrulemaking.html

United States Environmental Protection Agency. (2010c). EPA and NHTSA Announce a First Step in the Process for Setting Future Greenhouse Gas and Fuel Economy Standards for Passenger Cars and Light Trucks. Office of Transportation and Air Quality. EPA-420-F-10-051. Retrieved from http://www.epa.gov/otaq/climate/regulations/420f10051.htm 


\section{APPENDIX A. PHONE INTERVIEW QUESTIONS}

\section{Role}

1) What has been your role in exploring thresholds for GHG emissions?

2) Historically, how has South Coast been involved in CEQA review and how will that change now with GHG thresholds?

\section{Threshold Type}

3) To begin, can you summarize for us the thresholds you developed and what you are recommending to lead agencies for evaluating GHG emissions under CEQA?

o What type of methods and analysis did you use for developing your threshold?

o What information was required to conduct this analysis?

o What do you recommend for construction emissions?

o Do you have an off-site mitigation program?

4) Why has there not been any recent progress (no meetings since last year)?

5) When do you expect your board to adopt these thresholds?

6) Why did you decide to take this approach? What other approaches did you initially consider for evaluating GHG emissions under CEQA?

7) Do these thresholds correlate with your ozone precursor?

8) How do you see this threshold relating to other climate planning processes such as the CAPs and SCS for your region?
a. How are you working with the cities?
b. How have you supported greenhouse gas inventory efforts?
c. What guidance have you provided for CAPs?
d. Are you aware if any municipalities have set thresholds for GHG emissions?

9) Many other air districts plan to wait to provide any guidance for evaluating GHG emissions under CEQA. What was your main motivation for beginning this process? 
10) What specific assistance are you providing to lead agencies and project proponents for calculating if a project will have a significant impact?

11) What guidance documents did you rely on the most in developing your threshold?

12) What recommendations do you have for other air districts throughout the state that are considering adopting guidance? Do you have any specific recommendations for smaller districts?

13) What type of input have you received from cities and counties? What have been some of their general comments regarding your thresholds?

14) What do you think about legislation such as $A B 2313$ that is trying to set state-wide thresholds? Do you have any concerns about these type of efforts?

15) Do you think the methodology that you used is easily transferable to other districts? What concerns would you have for attempting this same analysis for smaller districts?

16) Is there any analysis that you have done that you think other air districts could use in developing their thresholds?

17) What was the cost of conducting this analysis? Contractors and staffing? Did you hire consultants or conduct this analysis in-house?

18) Have you done any analysis to quantify the expected cost of implementing these thresholds?

\section{Methods}

19) How do you plan to track progress over time?

\section{Process}

20) What process did your district take in developing these thresholds?

a. Was a stakeholder group formed?

i. If so, what organizations were involved?

ii. How many times did you meet?

iii. What key topics were covered?

iv. What were the outcomes of this group?

21) Did you hold any public workshops directly related to CEQA and climate change? 

a. If so, how many?
b. What was the format of the workshops?
c. What were (if any) the outcomes of the workshop?

22) Did you solicit input from other agencies, cities or counties within your jurisdiction?

23) In what ways has this process been successful?

24) What challenges did you encounter throughout this process?

25) Is there anything that you would have done differently?

26) What advice do you have for other air districts that are just getting started?

27) What are you currently working on and what are your next steps?

\section{Political Atmosphere}

28) Who are your key supporters? What have they praised?

29) Who is your key opposition? What are their concerns?

30) How would you characterize the political atmosphere of your jurisdiction?

31) How supportive is your air district of climate change initiatives?

32) How supportive is your is your board of climate change initiatives? 


\section{APPENDIX B. EMAILED SURVEY QUESTIONS}

1) What involvement has your air district had in addressing greenhouse gas emissions under CEQA?

2) Please broadly describe how your air district has been working with the cities and count(ies) in your jurisdiction on climate planning.

a. Has your district been involved or assisted with the greenhouse gas emission inventories for the cities and count(ies) in your jurisdiction? If yes, how so?

b. Has your district been involved or assisted with developing Climate Action Plans or the regional Sustainable Communities Strategy? If yes, how so?

c. To your knowledge, have any of the city or county agencies set greenhouse gas thresholds? If so, was your air district involved in this process? How does this threshold relate to the guidance you are or plan to provide?

3) Have City and County agencies asked your air district for guidance in evaluating GHG emissions under CEQA? If so, how have you responded?

4) Does your district review projects under CEQA?

a. If yes, how many projects does your district review in a typical year?

b. What is the typical range in sizes of projects in your jurisdiction?

5) How are you determining significance in the absence of thresholds?

6) Are you requiring quantification of GHG emissions for projects?

7) Does your district plan to do include GHG emissions in your CEQA guidance?

8) Have you looked at what the BAAQMD, SCAQMD, SJVUAPCD or other districts have done to help inform the guidance your district will provide? If so, how do you plan to use what they have done to inform the guidance your district provides?

9) How supportive is your is your board of climate change initiatives?

10) What are the main concerns or challenges your district has for providing guidance for evaluating GHG emissions under CEQA?

11) Have you found any guidance for determining significance of GHG emissions under CEQA from the following agencies useful:

a. OPR 

b. AG
c. $\mathrm{CARB}$
d. CAPCOA

12) What type of assistance would be helpful to your air district to provide guidance on GHG emissions under CEQA? 